\title{
Limb myology and muscle architecture of the Indian rhinoceros Rhinoceros unicornis and the white rhinoceros Ceratotherium simum (Mammalia: Rhinocerotidae)
}

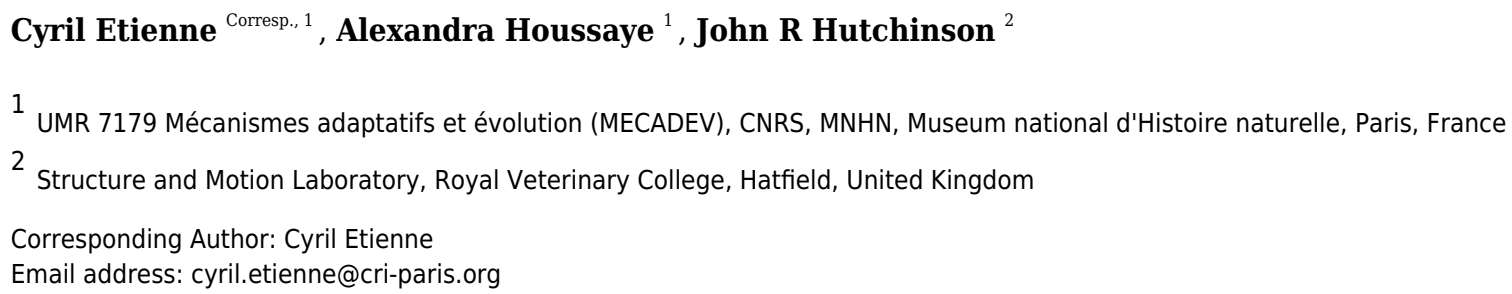

Land mammals support and move their body using their musculoskeletal system. Their musculature usually presents varying adaptations with body mass or mode of locomotion. Rhinocerotidae is an interesting clade in this regard, as they are heavy animals potentially reaching three tons but are still capable of adopting a galloping gait. However, their musculature has been poorly studied. Here we report the dissection of both forelimb and hindlimb of one neonate and one adult each for two species of rhinoceroses, the Indian rhinoceros (Rhinoceros unicornis) and the white rhinoceros (Ceratotherium simum). We show that their muscular organisation is similar to that of their relatives, equids and tapirs, and that few evolutionary convergences with other heavy mammals (e.g. elephants and hippopotamuses) are present. Nevertheless, they show clear adaptations to their large body mass, such as more distal insertions for the protractor and adductor muscles of the limbs, giving them longer lever arms. The quantitative architecture of rhino muscles is again reminiscent of that of horses and tapirs, although contrary to horses, the forelimb is much stronger than the hindlimb, which is likely due to its great role in body mass support. Muscles involved mainly in counteracting gravity (e.g. serratus ventralis thoracis, infraspinatus, gastrocnemius, flexores digitorum) are usually highly pennate with short fascicles facilitating strong joint extension. Muscles involved in propulsion (e.g. gluteal muscles, gluteobiceps, quadriceps femoris) seem to represent a compromise between a high maximal isometric force and long fascicles, allowing a reasonably fast and wide working range. Neonates present higher normalized maximal isometric force than the adults for almost every muscle, except sometimes for the extensor and propulsor muscles, which presumably acquire their great force-generating capacity during the growth of the animal. Our study clarifies the way the muscles of animals of cursorial ancestry can adapt to support a greater body mass and calls for further investigations in other clades of large body mass. 


\section{Limb myology and muscle architecture of the Indian}

2 rhinoceros Rhinoceros unicornis and the white

3 rhinoceros Ceratotherium simum (Mammalia:

4 Rhinocerotidae)

5

6

7 Cyril Etienne $^{1}$, Alexandra Houssaye ${ }^{1}$, John R. Hutchinson ${ }^{2}$

8

$9 \quad{ }^{1}$ UMR 7179 Mécanismes adaptatifs et Evolution, Muséum National d'Histoire Naturelle, Centre 10 National de la Recherche Scientifique, Paris, France

$11{ }^{2}$ Structure and Motion Laboratory, Department of Comparative Biomedical Sciences, The Royal

12 Veterinary College, Hatfield, United Kingdom

13

14

15

16

17

18

19

20
Corresponding Author:

Cyril Etienne $^{1}$

57 rue Cuvier - CP 55, Paris, 75005, France

Email address: cyril.etienne@cri-paris.org 


\section{Abstract}

22

23

24

25

26

27

28

29

30

31

32

33

34

35

36

37

38

39

40

41

42

43

44

45

46

47

48
Land mammals support and move their body using their musculoskeletal system. Their musculature usually presents varying adaptations with body mass or mode of locomotion. Rhinocerotidae is an interesting clade in this regard, as they are heavy animals potentially reaching three tons but are still capable of adopting a galloping gait. However, their musculature has been poorly studied. Here we report the dissection of both forelimb and hindlimb of one neonate and one adult each for two species of rhinoceroses, the Indian rhinoceros (Rhinoceros unicornis) and the white rhinoceros (Ceratotherium simum). We show that their muscular organisation is similar to that of their relatives, equids and tapirs, and that few evolutionary convergences with other heavy mammals (e.g. elephants and hippopotamuses) are present. Nevertheless, they show clear adaptations to their large body mass, such as more distal insertions for the protractor and adductor muscles of the limbs, giving them longer lever arms. The quantitative architecture of rhino muscles is again reminiscent of that of horses and tapirs, although contrary to horses, the forelimb is much stronger than the hindlimb, which is likely due to its great role in body mass support. Muscles involved mainly in counteracting gravity (e.g. serratus ventralis thoracis, infraspinatus, gastrocnemius, flexores digitorum) are usually highly pennate with short fascicles facilitating strong joint extension. Muscles involved in propulsion (e.g. gluteal muscles, gluteobiceps, quadriceps femoris) seem to represent a compromise between a high maximal isometric force and long fascicles, allowing a reasonably fast and wide working range. Neonates present higher normalized maximal isometric force than the adults for almost every muscle, except sometimes for the extensor and propulsor muscles, which presumably acquire their great force-generating capacity during the growth of the animal. Our study clarifies the way the muscles of animals of cursorial ancestry can adapt to support a greater body mass and calls for further investigations in other clades of large body mass. 


\section{Introduction}

50

51

52

53

54

55

56

57

58

59

60

61

62

63

64

65

66

67

68

69

70

71

72

73

74

75

76

77

78

79

80

81

82

83

84

85

86

87

88

Land mammals must support and move the weight of the entire body with their limbs, driven by the muscle-tendon units (e.g., Hildebrand, 1982; Biewener \& Patek, 2018). In ungulates, the forelimb and hindlimb each have a specific role: the forelimb, through its cranial position, tends to support about $60 \%$ of body weight and acts mainly in deceleration during steady-state locomotion, whereas the hindlimb has a smaller supportive role but a major propulsive one (Herr, Huang \& McMahon, 2002; Witte, Knill \& Wilson, 2004; Payne et al., 2005; Dutto et al., 2006; Ren et al., 2010; Biewener \& Patek, 2018).

Ungulates vary greatly in terms of mass and general proportions (e.g. a hippopotamus vs. a giraffe vs. a gazelle, Wilson \& Mittermeier, 2011). Their limb muscles thus vary in organisation (i.e. qualitative myology, notably where each muscle inserts on the bones), architecture (i.e. quantitative geometry of muscle fascicles, including e.g. fascicle length and pennation angle) and ultimately their general functional roles (Hildebrand et al., 1985; Biewener $\&$ Patek, 2018). For a given force, a muscle with a line of action close to a joint will typically generate a weaker moment due to a decreased moment arm, but the velocity of the movement, as well as its range of motion, will be increased (McClearn, 1985; Gans \& Gaunt, 1991; Pandy, 1999). This is useful for cursorial animals which rely on speed, but less useful for heavy animals (i.e. several tons) which counteract their body weight with large moments and forces (Biewener, 1989; Biewener \& Patek, 2018).

Muscle architecture is commonly described using several parameters (Alexander, 1974; Gans \& de Vree, 1987; Payne et al., 2005; Payne, Veenman \& Wilson, 2005; Myatt et al., 2012; Cuff et al., 2016; MacLaren \& McHorse, 2020). These include muscle mass and total belly length, the length of tendons and fascicles in the muscle, and the pennation angle of the fascicles relative to the line of action. These parameters can be used, for example, to estimate the muscle's physiological cross-sectional area (PCSA), which in turn can be used to estimate the maximal isometric force output of the muscle (Powell et al., 1984; Lieber \& Ward, 2011). Thus, quantitative muscle architecture of different groups of muscles can tell us much about an animal's potential limb functions. Parallel-fibred muscles have a greater working range than pennate muscles, but the latter have the advantage of being able to generate a greater force for the same muscle volume (Hildebrand et al., 1985; Biewener, 1990; Azizi, Brainerd \& Roberts, 2008; Biewener \& Patek, 2018). The organisation and architecture of the locomotor muscles of a species will represent a compromise between all those characteristics suiting the morphology and behaviour of that species, and taking into account its ancestry. Body mass in particular has a major impact on muscle architecture, because a muscle's maximal force output is a function of its cross-sectional area (scaling with linear dimensions squared), whereas mass increases proportionally to the volume of the animal (scaling with linear dimensions cubed; Biewener, 1989, 2005). In large animals, particular adaptations of the musculoskeletal system such as

Peer) reviewing PDF | (2021:01:57069:2:1:NEW 29 Mar 2021) 
89 changes in limb posture, bone shape and muscle organisation and architecture become necessary 90 (Alexander, 1985; Biewener, 1989, 2005).

91

92

93

94

95

96

97

98

99

100

101

102

103

104

105

106

107

108

109

110

111

112

113

114

115

116

117

118

119

120

121

122

123

124

125

126

127

128
Among large mammals, Rhinocerotidae comprises five extant species ranging from an average of $700 \mathrm{~kg}$ for Dicerorhinus sumatrensis, the Sumatran rhinoceros; to $2000 \mathrm{~kg}$ for Rhinoceros unicornis, the Indian rhino, and $2300 \mathrm{~kg}$ for Ceratotherium simum, the white rhino (Silva \& Downing, 1995; Dinerstein, 2011). The latter two species include adults exceeding three tons. Due to their heavy weight, rhinos have been described as graviportal, along with elephants and hippos (Hildebrand, 1982; Eisenmann \& Guérin, 1984; Alexander \& Pond, 1992). However, rhinoceroses present marked functional differences from elephants and hippos. Rhinos are all capable of attaining a full gallop, with a suspended phase where all four limbs are off the ground, reaching up to an estimated $\sim 7+\mathrm{ms}^{-1}$ for C. simum and $\sim 12 \mathrm{~ms}^{-1}$ for the lighter Diceros bicornis, the black rhinoceros (Garland, 1983; Alexander \& Pond, 1992), although empirical studies are very scarce. Hippopotamus and elephants cannot adopt a galloping gait (Dagg, 1973). Rhinoceros limbs are not as columnar as those of walking elephants, and still present a noticeable flexion of all joints when standing at rest (Christiansen \& Paul, 2001). This has led other studies to avoid their characterization as graviportal and classify them as mediportal instead, an intermediate category being defined by limbs primarily adapted for weight-bearing but incorporating some cursorial adaptations as well, commonly retained from a cursorial ancestor (Coombs, 1978; Becker, 2003; Becker et al., 2009).

The unusual form and function of rhinoceros limbs emphasise the need for a comprehensive anatomical study of their limb muscles, to better understand how their limbs sustain their large body weight. This would complement the extensive work recently performed on the morphology of rhinoceros limb bones (Mallet et al., 2019, 2020; Mallet, 2020; Etienne et al., 2020). In terms of both qualitative myology and quantitative architecture, rhinoceroses have been poorly studied. Haughton (1867) studied the limbs of a rhinoceros of two or three years old, captured from the wild near Calcutta and acquired by the Dublin zoo, and reported the mass of the individual muscles. It was likely an Indian rhinoceros (Rhinoceros unicornis), although the Javan (R. sondaicus) and Sumatran rhinoceroses may still have lived near that region at the time (Foose, Khan \& Strien, 1997; de Courcy, 2010). Beddard and Treves (1889) qualitatively studied two adult Sumatran rhinoceroses (Dicerorhinus sumatrensis), the lightest of all the living rhinos (Dinerstein, 2011). No detailed quantitative study of the limb muscles is available. Alexander \& Pond (1992) provided a few quantitative anatomical details for biomechanical analysis based on bone measurements and video analyses of a running white rhino (C. simum). In terms of myology, rhinos' relatives among the Perissodactyla, i.e. tapirs and equids, are more wellknown, although tapirs lack a quantitative characterization of their hindlimb (e.g. Murie, 1871; Campbell, 1936; Bressou, 1961; Barone, 1999, 2010; Brown et al., 2003; Payne et al., 2005; Payne, Veenman \& Wilson, 2005; Crook et al., 2008; Borges et al., 2016; Pereira et al, 2017). The musculature of the other heaviest mammals, i.e. elephants and hippopotamuses, has been

Peer) reviewing PDF | (2021:01:57069:2:1:NEW 29 Mar 2021) 
129

130

131

132

133

134

135

136

137

138

139

140

141

142

143

144

145

146

147

148

149

150

151

152

153

154

155

156

157

158

159

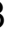

studied qualitatively, but never quantitatively (Miall \& Greenwood, 1878; Eales, 1928;

Mariappa, 1986; Weissengruber \& Forstenpointner, 2004; Fisher, Scott \& Naples, 2007; Fisher, Scott \& Adrian, 2010; Trenkwalder, 2013; Nagel et al., 2018).

Here we provide a description of the organization of the limb muscles of two species of rhinoceroses, and a quantitative characterisation of the architecture of those muscles, based on dissections of Ceratotherium simum and Rhinoceros unicornis. Those two species present a similar average mass, averaging around two tons (Silva \& Downing, 1995; Dinerstein, 2011); as such a heavy body mass induces an extremely high adaptive pressure (Hildebrand et al., 1985; Biewener, 1989, 1990; Biewener \& Patek, 2018), we might expect it to drive most of the muscular phenotype of our two species and thus to find few differences between them. However, the two species present several differences, like a different body profile: $C$. simum has a lowhanging head whereas $R$. unicornis carries its head higher (Dinerstein, 2011). They also display notable differences in limb bone shape (Guérin, 1980; Mallet et al., 2019, 2020; Etienne et al., 2020), and they live in different habitats, C. simum preferring open flatlands while $R$. unicornis is found in semi-open floodplains, swimming easily (Dinerstein, 2011). C. simum usually displays size dimorphism, with males larger than females, whereas $R$. unicornis displays dimorphism only in captivity, not in the wild, although size dimorphism in rhinos is difficult to quantify (Dinerstein, 2011). Therefore, we might still find some differences between our species that could be linked to their differences in morphology and habitat. At a larger scale, we expect that rhino musculature will share features linked to fast running with their close relatives, tapirs and equids; e.g. fast protractor muscles for all limbs and forceful propulsive muscles in the hindlimb, perhaps inherited from early perissodactyls (Radinsky, 1966; Gould, 2017). However, we expect rhinos, unlike their cousins, to show adaptations to sustain their large body mass that they might share through convergent evolution with Hippopotamus and elephants, mainly stronger extensor muscles, particularly in the forelimb, to counteract gravity. Finally, we expect neonate rhinoceroses' muscles to have a much greater relative force-generating capacity than those of adults, because ontogenetic scaling tends to render smaller animals relatively stronger (Carrier, 1995, 1996; Herrel \& Gibb, 2006).

Peer) reviewing PDF | (2021:01:57069:2:1:NEW 29 Mar 2021) 


\section{Materials \& Methods}

161

162

163

164

165

166

167

168

169

170

171

172

173

174

175

176

177

178

179

180

181

182

183

184

185

186

187

188

189

190

191

192

193

194

195

196

197

198

199

\section{Material}

Four specimens of rhinoceroses were dissected in this study (Table 1): two white rhinos ( $C$. simum) and two Indian rhinos (R. unicornis). For each species we studied a neonate and a female adult of around 40 years of age at death. All specimens died of natural causes or were euthanised by zoos for health issues unrelated to this study. For the adults, the limbs were separated from the carcass at the time of death and frozen until dissection; the neonates were frozen whole $(-20$ $\left.{ }^{\circ} \mathrm{C}\right)$. They were all thawed at $4{ }^{\circ} \mathrm{C}$ for at least two days before starting to dissect. The specimens were dissected at the Royal Veterinary College, Hawkshead campus, UK; only the left limbs were dissected except for the neonate $R$. unicornis for which we dissected the right limbs.

\section{Dissections}

The skin and superficial fascia were first removed to expose the surface muscles. Each muscle was identified, labelled, photographed and carefully dissected from origin to insertion, including any tendon, which was then separated from the muscle belly. Muscle bellies and tendons were cleaned of fat and aponeuroses, weighed using electronic scales to the nearest $0.1 \mathrm{~g}$, and measured using a measuring tape ( $\pm 1 \mathrm{~mm}$, adults) or digital callipers $( \pm 0.1 \mathrm{~mm}$, neonates) from the proximal to the distal end. Muscle fascicles were exposed by cutting along the length of the belly in multiple locations, and their lengths measured at random intervals within the muscle belly. Between three and 10 measurements were made for each muscle for repeatability, with more measurements for larger muscles. Pennation angles of fascicles were also measured using a protractor $\left( \pm 5^{\circ}\right)$; again, between three and 20 measures were taken depending on the muscle and its size.

\section{Insertion areas}

Origin and insertion areas of all the muscles were estimated mainly by observation of the in situ photographs, and occasionally by comparisons with previous works on rhinos (Haughton, 1867; Beddard \& Treves, 1889) as well as what is known in horses from Barone $(1999,2010)$. Considering that we studied two species of rhinos, the insertion areas are not meant to be species-specific but rather a consensus of what is observed in adult rhinocerotids. If differences between our two species were noted, they were reported.

\section{Quantitative parameters}

Muscle volume was estimated by dividing its mass by a density of $1.06 \mathrm{~g} \mathrm{~cm}^{-3}$ (Mendez \& Keys, 1960; see also e.g. Brown et al., 2003; Payne et al., 2005; MacLaren \& McHorse, 2020).

Peer) reviewing PDF | (2021:01:57069:2:1:NEW 29 Mar 2021) 
200 Average fascicle length (AFL) and pennation angle for each muscle were calculated. PCSA was 201 calculated using the following formula:

202

203

204

205

206

207

208

209

210

21

212

213

214

215

216

217

218

219

220

$$
P C S A=\frac{\text { Muscle mass } * \cos (\text { pennation angle })}{\text { density } * A F L}
$$

The maximal isometric force (Fmax) capacity of each muscle was estimated by multiplying the PCSA by the maximal isometric stress of vertebrate skeletal muscle $(300 \mathrm{kPa}$ (Woledge, Curtin \& Homsher, 1985)). This value was then normalized by dividing it by the weight of the animal (in Newtons; = body mass * $9.81 \mathrm{~m} \mathrm{~s}^{-2}$ ). The AFL was also normalized by dividing it by the mean of the AFL of all the muscles in the limb. This allowed comparisons of Fmax and AFL between specimens of different masses, particularly between adults and neonates. Normalized Fmax was compared between the species and the developmental stages using a Student's t-test with the logarithm of the values, using the stats.ttest_ind function of the SciPy Python package (see File S1 for code). If the value for a muscle was missing in any of the two specimens that were compared with the t-test, the muscle was removed in the other specimen compared as well, in order to compare identical sets of muscles. This was the case for eight muscles out of 63 when comparing between both adults, 20 when comparing between both neonates, 11 when comparing both $C$. simum individuals, and 20 when comparing both $R$. unicornis specimens. 


\section{Results}

222

223

224

225

226

227

228

229

230

231

232

233

234

235

236

237

238

239

240

241

242

243

244

245

246

247

248

249

250

251

252

253

254

255

256

257

258

259
In the Results section, we start by making comparisons of qualitative myology between rhinos and their close relatives among perissodactyls (i.e. tapirs and equids). Hippopotamuses and elephants are included as well, because they share with rhinoceroses a large body mass and might thus present similar size-related adaptations. When relevant, large bovids are also included in the comparisons. We then report on the quantitative architecture of the limb muscles of our four specimens.

\section{Comparative anatomy of the limb muscles}

$\underline{\text { Forelimb }}$

The anatomy of each muscle of the forelimb was recorded (Table 2, Figures 1, 2), and their origin and insertion on the bones were determined (Figs. 3, 4, 5). Several muscles were damaged (e.g. during limb removal at post-mortem site) and their quantitative parameters could not be measured. These were the rhomboidei (RHB) and the extensor carpi radialis (ECR) in the adult $R$. unicornis, and the serrati ventrales (SV) in the neonate $R$. unicornis. Some muscles were not found at all in some specimens, these were the brachialis (BR) and flexor carpi ulnaris (FCU) in the adult $R$. unicornis, the extensor carpi obliquus (ECO) in the neonate $R$. unicornis, the brachioradialis (BRA) in the neonate $C$. simum and the tensor fasciae antebrachiae (TFA) in both neonates. We found that muscles were often less clearly differentiated in neonate rhinos. The serrati ventrales could not be separated into the pars cervicis (SVC) and the pars thoracis (SVT) in both neonates but were distinct in both adults. The same applied to the pars acromialis (DLA) and pars scapularis (DLS) of the deltoideus (DL) in the neonate C. simum, and the cranial and caudal parts of the coracobrachialis (CB) in both neonates. The four pectorales were all present, but were difficult to separate in neonates again, especially the two pectorales superficiales (the pectoralis descendens and the pectoralis transversus, PCD and PCT) and the two pectorales profundi (the pectoralis ascendens and the subclavius, PCA and SU). The anconeus (AN) was merged with the triceps brachii caput mediale (TM) in all specimens except the neonate $R$. unicornis. The flexor carpi radialis (FCR) and flexor carpi ulnaris were also impossible to separate in the neonates. The ulnar head of the flexor digitorum profundus (FDPF) was well differentiated in adult rhinoceroses, but not in neonates. The pronator teres was identified only in the adult $C$. simum as a reduced strip, almost entirely tendinous. $M m$. teres minor, palmaris longus, pronator quadratus, supinator and extensor pollicis longus et indicis were not found in any specimen.

Extrinsic muscles of the forelimb

Peer) reviewing PDF | (2021:01:57069:2:1:NEW 29 Mar 2021) 
260

261

262

263

264

265

266

267

268

269

270

271

272

273

274

275

276

277

278

279

280

281

282

283

284

285

286

287

288

289

290

291

292

293

294

295

296

297

298

299

The omotransversarius (OT) ran very close to the brachiocephalicus (BC) down the neck, before inserting proximal to it on the humerus (Figs. 1B, 4), with an apparent insertion on the distal scapular spine via an aponeurosis. This was already described by Haughton (1867) in $R$.

unicornis, and distinguishes rhinoceroses from most other ungulates and elephants. In the other perissodactyls however, the muscle's aponeurosis goes from the scapular spine to the humeral crest (Windle \& Parsons, 1902; Bressou, 1961; Fisher, Scott \& Naples, 2007; Barone, 2010). The muscle's diameter was constant across its length, unlike in equids where it presents a triangular shape. The brachiocephalicus inserted at the proximal humeral crest, and tended to fuse partially with the coracobrachialis (CB) and the omotransversarius in the neonate $R$. unicornis when inserting; this fusion was not observed in the other specimens. It is composed of one head only, unlike what is generally observed in artiodactyls and in elephants but similar to other perissodactyls (Miall \& Greenwood, 1878; Campbell, 1936; Fisher, Scott \& Naples, 2007; Barone, 2010).

In our rhinoceroses, the pectorales superficiales (transversus and descendens, PCD and PCT) inserted next to the brachiocephalicus (BC) on the humeral crest (Figs. 1A, 4), like in other ungulates and in elephants (Miall \& Greenwood, 1878; Campbell, 1936; Fisher, Scott \& Naples, 2007; Barone, 2010; Trenkwalder, 2013). Contrary to horses, their insertions do not merge with that of the brachiocephalicus. In hippopotamuses, the pectoralis descendens and transversus are entirely fused and cannot be separated; this is not the case in rhinoceroses. The origins of the subclavius (SU) and of the pectoralis ascendens (PCA) are also like those of other ungulates and elephants. Unlike in those species however, those muscles merge before inserting on the humerus. This means that the subclavius's main insertion is on the proximal humerus, and not on the scapula as in other species of large ungulates and in elephants (Fig. 4). The subclavius may still have attached to the scapula through fascia in our rhinos, although this was difficult to determine. In horses, Payne, Veenman \& Wilson (2005) reported an insertion of the subclavius on the greater tubercle, but Barone (2010) mentioned only the scapula, similar to tapirs (Campbell, 1936; Bressou, 1961).

The serrati ventrales (SVC and SVT) of rhinoceroses do not differ qualitatively from other ungulates and elephants, nor does the latissimus dorsi (LD), which ran along the teres major (TRM) as a thin tendon and inserted with it onto the teres major tuberosity (Murie, 1871; Miall \& Greenwood, 1878; Eales, 1928; Campbell, 1936; Bressou, 1961; Fisher, Scott \& Naples, 2007; Barone, 2010). The trapezius (TP) could only be separated into a pars cervicis and a pars thoracis in the neonate $C$. simum, both parts were inseparable in the other specimens. The rhomboideus (RHB) is similar to what is observed in other perissodactyls and large ungulates, but in elephants the rhomboideus is divided into several parts, due perhaps to their phylogenetic distance from the others (Trenkwalder, 2013).

Muscles of the shoulder

Peer) reviewing PDF | (2021:01:57069:2:1:NEW 29 Mar 2021) 
300

301

302

303

304

305

306

307

308

309

310

311

312

313

314

315

316

317

318

319

320

321

322

323

324

325

326

327

328

329

330

331

332

333

334

335

336

337

338

Like in elephants, Hippopotamus, suids, and Dicerorhinus, the supraspinatus (SSP) presented only one insertion in our rhinos, on the greater tubercle (Fig. 4), although Hippopotamus may present a minority of fibres inserting on the lesser tubercle as well, depending on the studies. A second insertion is observed on the lesser tubercle in horses and tapirs, as well as in bovids (Gratiolet \& Alix, 1867; Miall \& Greenwood, 1878; Beddard \& Treves, 1889; Eales, 1928; Campbell, 1936; Fisher, Scott \& Naples, 2007; Barone, 2010; Trenkwalder, 2013; MacLaren \& McHorse, 2020). It is to be noted that giraffes also present a unique insertion of the supraspinatus (C. Basu comm. pers.). Unlike what is observed in horses and bovids, the infraspinatus's (ISP) insertion on the greater tuberosity is not separable in two parts; apart from this, the muscle does not differ from what is observed in other perissodactyls, large bovids, hippopotamuses and elephants.

Unlike results reported by Haughton (1967), we found two distinct parts of the deltoideus (DL), in the adults of both species: the pars acromialis (DLA) and pars scapularis (DLS). This is similar to what is observed in elephants, bovids, and Choeropsis (Eales, 1928; Campbell, 1936; Fisher, Scott \& Naples, 2007; Barone, 2010; Trenkwalder, 2013). In Hippopotamus, Gratiolet \& Alix (1867) reported that the deltoideus is not divided into those two parts. This division was not reported in a juvenile tapir by MacLaren \& McHorse (2020), but it was by Bressou (1961); it may serve to provide finer control on the directions of the forces exerted by the muscle. Notably, the pars acromialis inserts quite proximally on the scapular spine in rhinoceroses, close to the pars scapularis (Fig. 3A); this may be because the acromion is absent on the scapula of rhinoceroses (Guérin, 1980). Alternatively, because the muscle inserts more proximally on the spine this may have reduced the forces exerted on the acromion and allowed its eventual reduction.

In our rhino specimens, the subscapularis (SSC) was single-headed and mixed with fibrous fibres, as in horses. The muscle does not seem to differ much from that in other large ungulates and elephants, except hippopotamuses and domestic bovids, in which the muscle is partially split into two or more parts (Miall \& Greenwood, 1878; Eales, 1928; Campbell, 1936; Fisher, Scott \& Naples, 2007; Barone, 2010; Trenkwalder, 2013; MacLaren \& McHorse, 2020). The teres major (TRM) is similar to that of other perissodactyls or large ungulates (Campbell, 1936; Fisher, Scott \& Naples, 2007; Barone, 2010; Trenkwalder, 2013; MacLaren \& McHorse, 2020). The teres minor was not found; it is possible it merged with the infraspinatus (ISP) of which can be deemed an accessory muscle. Miall \& Greenwood (1878), Eales (1928) and Fisher, Scott \& Naples (2007) did report that the teres minor tends to blend with the infraspinatus in elephants and Choeropsis. Neither Haughton (1867) nor Beddard \& Treves (1889) reported a teres minor in rhinoceroses, which is consistent with our hypothesis.

Peer] reviewing PDF | (2021:01:57069:2:1:NEW 29 Mar 2021) 
339

340

341

342

343

344

345

346

347

348

349

350

351

352

353

354

355

356

357

358

359

360

361

362

363

364

365

366

367

368

369

370

371

372

373

374

375

376

377

378

We observed that the coracobrachialis (CB) was split in two parts in our specimens, cranial and caudal, as in equids and bovids (Barone, 2010), inserting close to one another on the craniomedial humerus. Bressou (1961) also reported an incomplete division in the tapir, but other studies did not (Murie, 1871; Campbell, 1936; MacLaren \& McHorse, 2020). Trenkwalder (2013) mentioned an insertion in two parts in Loxodonta, but Eales (1928) stated that the muscle is in one part, and Miall \& Greenwood (1878) did not report subdivisions in Elephas, either. Only Trenkwalder (2013) studied an adult specimen, whereas the latter two studies were respectively of a foetus and a juvenile, so the subdivision of the muscles may have been yet to develop, as in our neonate specimens. This division is not reported in Hippopotamidae, nor, interestingly, in Dicerorhinus (Gratiolet \& Alix, 1867; Beddard \& Treves, 1889; Campbell, 1936; Macdonald et al., 1985; Fisher, Scott \& Naples, 2007).

Muscles of the arm

In our specimens, the biceps brachii (BB) presented only one head, as in most mammals, and inserted on the radial tuberosity via a flat, very thick tendon (Figs. 1B, 5; Barone, 2010). In tapirs the insertion is on both the proximomedial radial head and medial coronoid process of the ulna (Murie, 1871; Bressou, 1961; MacLaren \& McHorse, 2020). In elephants, it has been noted as originating on the articular capsule rather than the coracoid process, and inserting generally on the ulna and sometimes on the radius (Miall \& Greenwood, 1878; Eales, 1928; Trenkwalder, 2013). The brachialis (BR) is like that of other perissodactyls, large ungulates and elephants, although it sometimes inserts on the ulna rather than the radius, which does not fundamentally change the muscle's action. (Gratiolet \& Alix, 1867; Miall \& Greenwood, 1878; Eales, 1928; Campbell, 1936; Fisher, Scott \& Naples, 2007; Trenkwalder, 2013; MacLaren \& McHorse, 2020).

The triceps brachii consisted of three heads (longus, mediale, laterale; TLo, TLa, TM); an accessory head was also observed only in the neonate $C$. simum, caudal to the long head (Fig. 2), although this may actually correspond to the tensor fasciae antebrachiae (TFA). The caput longum and caput laterale of the triceps are similar to those observed in other perissodactyls or large ungulates and elephants. The caput longum was partially divided into a cranial and caudal head in the adult specimens, this is reminiscent of what has sometimes been reported in tapirs and hippopotamuses (Campbell, 1936; Bressou, 1961); the accessory head observed in the neonate $C$. simum may also correspond to the caudal of those heads. The caput mediale seemed to merge with the anconeus (AN) in all our specimens except our neonate $R$. unicornis; this has also sometimes been reported in tapirs and Choeropsis (Campbell, 1936; Fisher, Scott \& Naples, 2007). The caput longum is by far the strongest one in rhinos (see Quantitative characterisation), followed by the caput laterale and then the caput mediale, the same pattern has been observed in horses, tapirs, elephants and most ungulates (Miall \& Greenwood, 1878; Eales, 1928; Watson \& Wilson, 2007; Barone, 2010; MacLaren \& McHorse, 2020). Like in horses, the tensor fasciae 
379

380

381

382

383

384

385

386

387

388

389

390

391

392

393

394

395

396

397

398

399

400

401

402

403

404

405

406

407

408

409

410

411

412

413

414

415

416

417

418

antebrachiae originates and inserts close to the triceps caput longum (Barone, 2010). This is similar to what Eales (1928) and Trenkwalder (2013) reported in Loxodonta; other studies did not report this muscle.

\section{Muscles of the forearm}

We observed a brachioradialis (BRA) in three of our specimens, the neonate $C$. simum being the only exception; this is unusual in large ungulates. It is however present in tapirs as well as in elephants and sometimes in Hippopotamus (Miall \& Greenwood, 1878; Eales, 1928; Campbell, 1936; Fisher, Scott \& Naples, 2007; Barone, 2010; Trenkwalder, 2013; Nagel et al., 2018; MacLaren \& McHorse, 2020). The muscle is particularly proximal in rhinos (Figs. 1B, 4, 5), originating and inserting very close to the brachialis (BR), to the point that both muscles may have merged in the adult $R$. unicornis.

The extensor carpi radialis (ECR) and extensor carpi obliquus (ECO) did not differ qualitatively from what is observed in other extant ungulates. The latter, which consists of the fusion of the abductor pollicis longus and extensor pollicis brevis, is particularly gracile, as usual in ungulates; it was however noted to be "strong" in Loxodonta (Nagel et al., 2018). For the ulnaris lateralis (or extensor carpi ulnaris, UL), we observed a caudal path and an insertion on the pisiform bone, meaning that this muscle clearly acts as a flexor of the carpus in both studied species (Fig. 1B). This is also observed in large artiodactyls and in equids, but not in tapirs, in which the muscle acts as an extensor due to its insertion on the fifth metacarpal (Fisher, Scott $\&$ Naples, 2007; Barone, 2010; MacLaren \& McHorse, 2020). In adult rhinos it is the strongest muscle of the forearm (see Quantitative characterisation); this is in accordance with that which was found in tapirs and horses; it appears to be weak in Choeropsis (Haughton, 1867; Brown et al., 2003; Fisher, Scott \& Naples, 2007). In both species, the extensor digitorum communis's (EDC) main origin was on the humerus, above the radial fossa. It also presented a small radial head in our $C$. simum specimens, as in horses and Dicerorhinus, although it extends distally on the ulna in the latter. Our two R. unicornis specimens, along with hippopotamuses and elephants, seem to lack this radial head; some studies reported it Tapirus terrestris and T. indicus, others did not in the same species (Murie, 1871; Beddard \& Treves, 1889; Windle \& Parsons, 1902; Campbell, 1936; Fisher, Scott \& Naples, 2007; Barone, 2010; Pereira et al., 2017; Nagel et al., 2018; MacLaren \& McHorse, 2020). This radial head might correspond to the extensor pollicis longus, as suggested by Bressou (1961) in tapirs. Given its small size, its presence or absence is most likely the result of evolutionary variation rather than a functional constraint. The extensor digitorum lateralis's (EDLaF) main origin was clearly on the lateral humeral condyle, similar to that observed in most ungulates, including tapirs but not equids, where the origin is exclusively in the lateral shaft of the radius-ulna (Beddard \& Treves, 1889; Campbell, 1936; Barone, 2010; Nagel et al., 2018; MacLaren \& McHorse, 2020). The muscular belly still attached on the lateral radius and ulna while passing down the forearm.

PeerJ reviewing PDF | (2021:01:57069:2:1:NEW 29 Mar 2021) 
419

420

421

422

423

424

425

426

427

428

429

430

431

432

433

434

435

436

437

438

439

440

441

442

443

444

445

446

447

448

449

450

451

452

453

454

455

456

457

458

The humeral origins of the four flexors of the carpus and digits were difficult to differentiate, but anatomical observations were consistent with the pattern known for other perissodactyls (Fig. 4; Campbell, 1936; Bressou, 1961; Barone 1999, 2010; MacLaren \& McHorse, 2020). The flexor carpi ulnaris (FCU) was not found at all in the adult $R$. unicornis, whereas in the neonate it was closely appressed to the flexor digitorum profundus (FDPF), with which the flexor carpi ulnaris might have merged, as their origins on both the humerus and the ulna are close (Figs. 1, 4, 5). This muscle does not differ further from what is observed in other perissodactyls, large ungulates and elephants (Beddard \& Treves, 1889; Fisher, Scott \& Naples, 2007; Barone, 2010; Nagel et al., 2018; MacLaren \& McHorse, 2020). The flexor carpi radialis (FCR) is similar in rhinos to that generally observed in large ungulates and elephants, and it is particularly weak, as in horses and tapirs (Brown et al., 2003; MacLaren \& McHorse, 2020). In adults, the flexor digitorum profundus of the forelimb presented two heads, one humeral and one ulnar, separated until the tendon, where they merged with the tendon of the superficialis (FDSF) in our adult $C$. simum only. Haughton (1867) reported the same fusion in what was likely a specimen of $R$. unicornis, which means that these muscles could present a degree of variation in rhinoceroses. The flexor digitorum profundus is highly variable in mammals: the radial head observed in tapirs and equids was here absent or greatly reduced. Beddard \& Treves (1889) noted only a humeral head in Dicerorhinus. Hippopotamus seems to present a radial, an ulnar and two humeral heads, Loxodonta an ulnar and two humeral heads, and Elephas only one or several humeral heads (Miall \& Greenwood, 1878; Campbell, 1936; Barone, 2010; Nagel et al., 2018; MacLaren \& McHorse, 2020).

\section{$\underline{\text { Hindlimb }}$}

The anatomy of each muscle of the hindlimb was recorded (Table 3, Figs. 6, 7), and their origin and insertion on the bones were determined (Figs. 8, 9). As for the forelimb, several muscles were damaged before or during dissection: the popliteus (PP) in the adult $C$. simum, and theobturator et gemelli (OG) in the neonate $R$. unicornis. Others were not found at all: the psoas minor (PMN) in both R. unicornis, the gluteus profundus (GPF), popliteus and extensor digitorum lateralis $(\mathrm{EDLaH})$ in the neonate $R$. unicornis. In the neonate $C$. simum, both flexores digitorum were merged and impossible to separate, as well as the two heads of the gastrocnemius (GC). The piriformis, quadratus femoris, articularis coxae, soleus, tibialis caudalis, extensor hallucis longus and fibularis brevis were not found in any specimen.

\section{Muscles of the pelvis}

The iliacus (IL) and the psoas major (PMJ) are similar to what is observed in other perissodactyls and in large ungulates and elephants; they did not merge completely but inserted close to one another on the lesser trochanter (Figs. 6A, 8). The fusion of these muscles seems

Peer) reviewing PDF | (2021:01:57069:2:1:NEW 29 Mar 2021) 
459

460

461

462

463

464

465

466

467

468

469

470

471

472

473

474

475

476

477

478

479

480

481

482

483

484

485

486

487

488

489

490

491

492

493

494

495

496

497

498

more prominent in Hippopotamus and Bos taurus than in perissodactyls; the degree of fusion in elephants is unclear (Gratiolet \& Alix, 1867; Murie, 1871; Miall \& Greenwood, 1878; Eales, 1928; Bressou, 1961; Barone, 2010; Fisher, Scott \& Adrian, 2010). The psoas minor (PMN) inserted on the tuber coxae and differs from other taxa in that most of its fibres are continuous with the sartorius (SRT). This was already described by Beddard \& Treves (1889) in

Dicerorhinus, and therefore appears an apomorphy of Rhinocerotidae, although Haughton (1867) only noted in Rhinoceros that the sartorius originated "close" to the psoas minor, without further precision (see Murie, 1871; Miall \& Greenwood, 1878; Eales, 1928; Bressou, 1961; Payne et al., 2005; Barone, 2010; Fisher, Scott \& Adrian, 2010).

Three gluteal muscles were recorded: the gluteus superficialis (GSP), medius (GMD) and profundus (GPF; Fig. 6B); the accessorius was missing or merged with the profundus. They are in general similar to what is observed in horses and tapirs, with the exception that the superficialis was noted as being chiefly aponeurotic in tapirs and relatively weak in horses (Murie, 1871; Payne et al., 2005; Barone, 2010). Haughton (1867) recorded the superficialis as inserting on the fibula with tendinous strips for the greater and third trochanters in R. unicornis; we did not find such attachments. In Hippopotamus and it seems artiodactyls in general, the superficialis is merged with the gluteobiceps; this was not recorded here (Barone, 2010; Fisher, Scott \& Adrian, 2010). The gluteus medius and profundus do not differ from what is generally observed in perissodactyls or other large ungulates.

The obturator internus, obturator externus and the gemelli (OG) were fused and hard to distinguish from one another, and all inserted onto the trochanteric fossa. This has not been described in perissodactyls, large ungulates or elephants, to our knowledge. This arrangement may provide more stability to the hip joint, by ensuring that the abduction or adduction functions of the different components of this muscle regulate each other. The articularis coxae muscle was absent in our specimens and was not reported by Haughton (1867) in Rhinoceros nor Beddard \& Treves (1889) in Dicerorhinus, either. It has been reported in equids and hippopotamuses, but not in elephants, nor in most artiodactyls and in tapirs (Haughton, 1867; Murie, 1871; Miall \& Greenwood, 1878; Eales, 1928; Bressou, 1961; Barone, 2010; Fisher, Scott \& Adrian, 2010).

\section{Muscles of the thigh}

The tensor fasciae latae (TFL) formed a fibrous band around the knee, tightly bound with the sartorius (SRT), superficial to the quadriceps femoris (QF), similar to other large ungulates and elephants. It has been noted, albeit qualitatively, as being especially strong in tapirs, elephants and Hippopotamus, which is congruent with what we measured in rhinos (see Quantitative characterisation); this strength is most likely useful for the support and propulsion of a heavy animal (Haughton, 1867; Murie, 1871; Miall \& Greenwood, 1878; Eales, 1928; Bressou, 1961; Barone, 2010; Fisher, Scott \& Adrian, 2010). 
499

500

501

502

503

504

505

506

507

508

509

510

511

512

513

514

515

516

517

518

519

520

521

522

523

524

525

526

527

528

529

530

531

532

533

534

535

536

537

The biceps femoris and gluteofemoralis merged two thirds of the way down the femur, forming a gluteobiceps (GB) that inserted mainly on the lateral patella and tibia, via a fibrous band reaching up to the common calcaneal tendon (Figs. 6A, 7). The presence of a gluteobicepsis characteristic of numerous ungulates, although it is often simply called biceps femoris. In horses and tapirs, it is composed of three heads, but in rhinoceroses we only found two. In large artiodactyls, there are two heads as well, and the cranial one (the gluteofemoralis) merges with the gluteus superficialis (GSP). In elephants, Miall \& Greenwood (1878) and Eales (1928) reported only one head to the biceps femoris; it is unclear if the gluteofemoralis indeed merged with it. The semimembranosus (SM) is like that of horses, with an insertion going from the medial epicondyle of the femur to the proximal tibia, except that in rhinos it extends further distally. This is similar to what has been reported in tapirs and domestic bovids (Murie, 1871; Bressou, 1961; Barone, 2010). Unlike in tapirs though, the muscle originates from only one head. Beddard \& Treves (1889) noted a fusion with the semitendinosus (ST) in Dicerorhinus; this was not recorded here except in the neonate $R$. unicornis, although the two muscles were close in the other specimens. The semimembranosus appears quite different in Hippopotamus, where it merges with the adductor communis and inserts up to the crural fascia (Fisher, Scott \& Adrian, 2010). In elephants, the origin is in two parts, and the insertion is more distal, from the proximal tibia to the malleolus and the leg fasciae (Miall \& Greenwood, 1878; Eales, 1928). The semitendinosus is like that of the horse and tapir, with one head originating near the sacrum, the other on the ischial tuberosity; the two heads were more clearly separated in the adult $R$. unicornis than in the other specimens. The sacral head is not observed in Hippopotamus, domestic bovids, and Elephas, but Eales (1928) reported its presence in Loxodonta. The insertion is similar in all species (Murie, 1871; Miall \& Greenwood, 1878; Eales, 1928; Bressou, 1961; Barone, 2010; Fisher, Scott \& Adrian, 2010).

The quadriceps is composed of only three heads: the rectus femoris (RF), vastus lateralis (VL) and vastus medialis (VM). The vastus intermedius has been noted in horses as being split into two parallel parts that each tend to merge with the other corresponding vastus (Barone, 2010). This anatomy is likely the case in rhinoceroses as well, to a greater extent of merging that makes the intermedius indistinguishable in our specimens. The muscle is still distinguishable in tapirs and was reported by Haughton (1867) in Rhinoceros as well, pointing to a degree of individual variability for this muscle (Murie, 1871; Bressou, 1961). In Dicerorhinus, only two vasti are reported, and they are even reported to merge together and with the rectus femoris (Beddard \& Treves, 1889). Hippopotamus also lacks a separate vastus intermedius, but elephants possess all four heads of the quadriceps. As noted in tapirs, Hippopotamus and elephants and contrary to horses, the vastus lateralis was larger than the medialis (Gratiolet \& Alix, 1867; Murie, 1871; Miall \& Greenwood, 1878; Eales, 1928; Bressou, 1961; Payne et al., 2005; Fisher, Scott \& Adrian, 2010).

Peer) reviewing PDF | (2021:01:57069:2:1:NEW 29 Mar 2021) 
538

539

540

541

542

543

544

545

546

547

548

549

550

551

552

553

554

555

556

557

558

559

560

561

562

563

564

565

566

567

568

569

570

571

572

573

574

575

576

577

In our two specimens of $R$. unicornis the sartorius (SRT) consisted of two distinct heads, merging then separating in their middle section, one going from the inguinal ligament to the proximo-medial tibia, the other from the tuber coxae to the medial patella. Only the former was found in Ceratotherium. This arrangement in R. unicornis is surprising, and reminiscent of what is observed notably in domestic carnivores, where the sartorius indeed originates from the tuber coxae (Barone, 2010). The first head was similar to the only head observed in C. simum, Dicerorhinus, horses and tapirs (Murie, 1871; Beddard \& Treves, 1889; Bressou, 1961; Payne et al., 2005; Barone, 2010). Notably, Haughton (1867) also reported only one head in R. unicornis. The sartorius of domestic bovids and Hippopotamus is proximally divided in two. Miall \& Greenwood (1878) reported in Elephas a muscle like what we observed in C. simum but inserting on the leg fasciae close to the proximo-medial tibia. Eales (1928) reported the sartorius as being vestigial in Loxodonta. This muscle seems to be particularly weak in perissodactyls, although tapirs lack quantitative data (Murie, 1871; Bressou, 1961; Payne et al., 2005). Unlike Hippopotamus and domestic bovids but similar to horses, the insertion(s) of the sartorius in both species are not common with the gracilis's. The gracilis (GRC) is like that of Dicerorhinus, horses and tapirs in being very large and relatively flat, even though unlike in those species, it did not extend to the patella via fasciae in our species. The muscle is similar to that of other perissodactyls and elephants in its origin and insertion, except that it divides in two distally in tapirs (Murie, 1871; Miall \& Greenwood, 1878; Beddard \& Treves, 1889; Eales, 1928; Barone, 2010). In Hippopotamus, it is fused proximally with the semitendinosus and semimembranosus (Fisher, Scott \& Adrian, 2010).

The pectineus (PTN) consisted of two heads, one larger than the other, in the adult $R$. unicornis, whereas the other specimens showed only one head. It is similar in insertion and origin to that of horses, Dicerorhinus, Hippopotamus and elephants and to that which was reported by Bressou (1961) in tapirs. Conversely, Murie (1871) reported a much more proximal insertion on the trochanteric fossa in tapirs. The two heads observed in R. unicornis may correspond to the proximal subdivisions of this muscle observed in horses; alternatively, one of them could correspond to the adductor longus, which is said to have merged with the pectineus in horses and was not found separately in our rhinoceroses. Unlike in horses and tapirs, the adductor magnus and brevis (ADD) are merged in their proximal part. Compared to horses, the adductor magnus inserts more distally on the proximal medial tibia and around the fasciae of the knee, rather than on the femur (Murie, 1871; Bressou, 1961; Barone, 2010). This more distal insertion is reminiscent of that of the pectorales in the forelimb, and likely provides the muscle with a larger lever arm to adduct and potentially retract the leg as well. This is coherent with what Beddard \& Treves (1889) reported in Dicerorhinus, if their adductor magnus corresponds to our brevis and their longus to our magnus. Tapirs also present a tibial insertion of their adductores, although merged with the semimembranosus (SM; Bressou, 1961). In Hippopotamus, the adductores are merged, but distally, not proximally; their insertion is similar to that of rhinoceroses but the caudal part of the muscle merges with the semimembranosus 
578 (Fisher, Scott \& Adrian, 2010). Elephants do not present the distal insertion observed in 579 rhinoceroses, tapirs and Hippopotamus, as their adductores muscles insert more proximally, 580 exclusively on the femur (Miall \& Greenwood, 1878; Eales, 1928). This could be due to their 581 proportionally much longer legs.

582

583

Muscles of the leg

584

585

The tibialis cranialis's (TCR) insertion was on the medial cuneiform in our R. unicornis and $C$.

586 simum, slightly more proximal than that of Dicerorhinus, Hippopotamus, tapirs and horses,

587 which are placed on the medial cuneiform and on the second (Hippopotamus, Dicerorhinus T.

588 indicus in some studies) or third (T. indicus in other studies, horses) metatarsal (Murie, 1871;

589 Beddard \& Treves, 1889; Bressou, 1961; Barone, 2010; Fisher, Scott \& Adrian, 2010). This is

590

591

592

593

594

595

596

597

598

599

600

601

602

603

604

605

606

607

608

609

610

611

612

613

614

615

616

617 consistent with what Haughton (1867) reported in R. unicornis. In elephants, the muscle is partially merged with the extensor digitorum longus and may originate more distally on the tibial shaft (Miall \& Greenwood, 1878; Eales, 1928; Weissengruber \& Forstenpointner, 2004). It is weaker than the extensor digitorum longus, as is common in ungulates. We report here two fibulares muscles, the tertius (FIT) and the longus (FIL), although the fibulares muscles were exceedingly difficult to identify in our specimens, due to their distinct reduction. This is reminiscent of what is observed in horses, where the fibularis tertius is entirely tendinous and the longus absent (Barone, 2010). In tapirs, the tertius appears to merge with the tibialis cranialis (Bressou, 1961). The fibulares are well developed in Hippopotamus and in domestic bovids, and are also present in elephants where Weissengruber and Forstenpointner (2004) reported both a longus and a brevis.

The extensor digitorum longus's (EDLo) origin was on the extensor fossa (Fig. 8), similar to that observed in other perissodactyls and large ungulates, except in Dicerorhinus and in elephants where it originates on the lateral tibial condyle and even down to the tibial shaft in Elephas (Murie, 1871; Miall \& Greenwood, 1878; Beddard \& Treves, 1889; Eales, 1928; Bressou, 1961; Barone, 2010; Fisher, Scott \& Adrian, 2010). The extensor digitorum longus divided into two muscular bellies distally: the medial one inserted directly around the second metatarsal, the other split into three tendons, one for each distal phalanx (Fig. 6A). The insertions seem highly variable in the taxa we compared, and the different tendons were tightly bound and hard to differentiate, so a confusion on Haughton's (1867) part is not excluded. Haughton (1867) also reported in R. unicornis a division in two with a medial belly inserting proximally, but on the medial cuneiform rather than on the metatarsus. The lateral belly inserted only on the proximal phalanges of digits II and IV in his specimen, whereas in our specimens, the insertion was on the distal phalanx of each finger. In Dicerorhinus, a simple division in three tendons, one for each toe, has been observed, as in tapirs. Equids have only one tendon, for the single digit (Murie, 1871; Beddard \& Treves, 1889; Bressou, 1961; Barone, 2010). The extensor digitorum lateralis of the hindlimb (EDLaH) was not reported by Haughton (1867) nor Beddard \& Treves 
618 (1889). It is indeed a very gracile muscle, which may have been missing in their specimens, as in 619 our neonate $R$. unicornis. It is gracile in equids and tapirs as well, being almost fibrous in the 620 latter (Bressou, 1961; Payne et al., 2005). Its origin on the proximal fibula is similar to equids, 621 tapirs, domestic bovids and Hippopotamus; in elephants however, the muscle also originates 622 from the lateral collateral ligament and the tibial shaft. The insertion is similar to that of tapirs; in 623 horses it is on the third digit as it is the only remaining digit; in Hippopotamus the insertion is on 624 the distal phalanx of digits IV and V. Additionally, in horses and Hippopotamus the tendons 625 merge with that of the extensor longus, which was not observed here. In elephants, the insertion 626 is more proximal, on the metatarsals and the proximal phalanges of digits IV and V (Murie, 627 1871; Miall \& Greenwood, 1878; Beddard \& Treves, 1889; Eales, 1928; Bressou, 1961; Barone, 628 2010; Fisher, Scott \& Adrian, 2010).

629

630

631

The gastrocnemius (GC) does not differ qualitatively from what is observed in other perissodactyls and large ungulates, except that the lateral head (GCL) is stronger in rhinoceroses, in contrast with what was measured in horses, and qualitatively observed in Hippopotamus (See Quantitative characterisation; Payne et al., 2005; Fisher, Scott \& Adrian, 2010). In elephants,

634

635

636

637

638

639

640

641

642

643

644

645

646

647

648

649

650

651

652

653

654

655

656

657 the medial head (GCM) is divided in two proximally, and the origins are generally on the joint capsule rather than directly on the shaft. The soleus seemed to have merged with the gastrocnemius in our rhinos; it is reduced in the other perissodactyls and absent in Hippopotamus, which is consistent with our observations (Gratiolet \& Alix, 1867; Murie, 1871; Bressou, 1961; Payne et al., 2005; Fisher, Scott \& Adrian, 2010). This is in contrast with elephants where it is quite bulky (Weissengruber \& Forstenpointner, 2004). The popliteus (PP) is identical to that of the other perissodactyls or large ungulates.

The flexor digitorum superficialis of the hindlimb (FDSH) of $R$. unicornis is like that of other perissodactyls. That of $C$. simum is more peculiar by being entirely tendinous, and its tendon merges with that of the profundus in the adult specimen. In our neonate $C$. simum, both flexores digitorum were entirely fused. The superficialis has been noted as being reduced in tapirs, domestic bovids and equids (Bressou, 1961; Barone, 2010), although Payne et al. (2005) noted a relatively high PCSA for that muscle in horses, still not as high as that of the profundus (417 vs $666 \mathrm{~cm}^{2}$ ). Fisher, Scott \& Adrian (2010) did note that the superficialis lacks a distinct muscle belly and present few muscular fibres in Hippopotamus, but elephants appear to retain a clear muscular belly (Miall \& Greenwood, 1878; Eales, 1928; Weissengruber \& Forstenpointner, 2004). Perhaps the superficialis's function tends to be transferred to the profundus in perissodactyls and artiodactyls due to the larger space for attachment available on the caudal tibia, a tendency that is most extreme in C. simum. The origin of the superficialis is similar in all the clades we compared, except in elephants where the origin is more superficial, from fascia covering the joint capsule of the knee. We observed in all specimens a complete fusion of the flexores digitorum lateralis and medialis into a single flexor digitorum profundus of the hindlimb (FDPH),consistent with previous observations in rhinos (Haughton, 1867; Beddard \& Treves, 
658 1889). Rhinos seem unique in that regard, as in other perissodactyls, Hippopotamus, domestic

659

660

661

662

663

664

665

666

667

668

669

670

671

672

673

674

675

676

677

678

679

680

681

682

683

684

685

686

687

688

689

690

691

692

693

694

695

696

697

bovids and elephants, those muscles are separated but share their insertion tendons. The tibialis caudalis is absent in rhinos and tapirs and reduced in horses, but is present in Hippopotamus and elephants (Murie, 1871; Miall \& Greenwood, 1878; Beddard \& Treves, 1889; Eales, 1928; Bressou, 1961; Barone, 2010; Fisher, Scott \& Adrian, 2010).

\section{Quantitative characterisation}

A total of 3678 measurements were taken, from 270 muscles of four individual rhinoceroses (see Table S1). This includes 2029 measurements of fascicle length, 909 pennation angles, 264 muscle bellies weighed and measured, as well as 102 tendons. In the adult $R$. unicornis, the grand mean of the fascicle lengths of all muscles was $19.19 \mathrm{~cm}$ for the forelimb and $14.11 \mathrm{~cm}$ for the hindlimb. In the adult $C$. simum, it was $19.03 \mathrm{~cm}$ and $22.23 \mathrm{~cm}$ for forelimb and hindlimb respectively. In the neonate $R$. unicornis, it was $7.37 \mathrm{~cm}$ and $7.54 \mathrm{~cm}$. In the neonate $C$. simum, it was $9.73 \mathrm{~cm}$ and $9.07 \mathrm{~cm}$.

\section{Forelimb}

In the adult $C$. simum, the serrati ventrales (SVC and SVT) were partially damaged due to the separation of the limb from the body, but a sufficient part was salvaged to calculate average fascicle lengths and pennation angles. The masses of both muscles were extrapolated from their mass in $R$. unicornis, we considered that they take up the same proportion of the animal's mass. In the adult $C$. simum, only the humeral head of the flexor digitorum superficialis (FDSF) could be measured, due to damage to the ulnar head during dissection. The strongest muscles in the forelimb of the adult $R$. unicornis were the serrati ventrales (SVC and SVT), which were both close to being able to exert a force greater than the body weight of the rhino $(85 \%$ for the pars cervicis, 93\% for the pars thoracis, Fig. 10, Table S1). The biceps brachii (BB), supraspinatus (SSP), infraspinatus (ISP) and pectorales (PC) as a whole each were capable of exerting a force greater than half the body weight. The strongest muscle in C. simum was the long head of the triceps (TLo, 68\% of body weight, Fig. 10, Table S1). The latissimus dorsi (LD), infraspinatus (ISP) and serratus ventralis pars cervicis (SVC) were also able to exert a force greater than half the body weight. There was no statistical difference in average normalized Fmax between the adult specimens of the two species for the muscles of the forelimb (Student's t-test: $t=1.20 \mathrm{p}=$ $0.24)$.

In the forelimb of the neonate $R$. unicornis (Fig. 10, Table S1), three muscles were able to exert an estimated maximal force greater than body weight: the flexor digitorum profundus (FDPF, 157\%), infraspinatus (ISP, 148\%), and biceps brachii (BB, 145\%). In the forelimb of the neonate $C$. simum (Fig. 10, Table S1), there were 10 such muscles: the biceps brachii (BB, 203\%), supraspinatus (SSP, 168\%), triceps brachii caput longum (TLo, 160\%), infraspinatus

Peer] reviewing PDF | (2021:01:57069:2:1:NEW 29 Mar 2021) 
698 (ISP, 160\%), latissimus dorsi (LD, 156\%), trapezius (TP, 155\%), rhomboidei (RHB, 123\%), 699 flexor carpi ulnaris (FCU, 115\%); pectorales (PC, 114\%) and ulnaris lateralis (UL, 103\%).

700 There was no statistical difference in average normalized Fmax between the neonate specimens 701 of the two species for the muscles of the forelimb $(t=-0.46, p=0.65)$. Neonate individuals had a 702 greater average normalized Fmax than adults of the same species for the muscles of the forelimb $703(\mathrm{t}=-5.75$ for C. simum, $\mathrm{t}=-4.17$ for R. unicornis, $\mathrm{p}<0.001$ for both species). Almost all 704 muscles indeed presented a greater relative maximal force capacity in neonates, with the 705 exception of the supraspinatus (SSP) and flexor digitorum superficialis (FDSF) in R. unicornis 706 and the serrati ventrales (SV) and flexor digitorum profundus (FDPF) in C. simum.

707

708

709

710

711

712

713

714

715

716

717

718

719

720

721

722

723

724

725

726

727

728

729

730

731

732

733

734

735

736

737

In the forelimb, the muscles with the relatively longest fascicles were the omotranversarius (OT) and brachiocephalicus (BC, Fig. 11). Among the extrinsic muscles, the serrati ventrales (SV, SVC, SVT) and the trapezius (TP) had particularly low normalized AFL. The infraspinatus (ISP), supraspinatus (SSP) and subscapularis (SSC) had a similar normalized AFL, shorter than the other muscles of the shoulder. The biceps brachii (BB) showed a relatively low normalized AFL compared to the triceps (TLo, TLa, TM), the tensor fasciae antebrachiae (TFA) and the brachialis (BR). The muscles of the forearm generally had shorter normalized AFL than average, except for the brachioradialis (BRA), the extensor carpi radialis (ECR) and the flexor carpi radialis (FCR).

\section{$\underline{\text { Hindlimb }}$}

Due to difficulties in the assignment of the homologies of the fibulares between our specimens, their values are not reported. In the hindlimb of the adult $R$. unicornis (Fig. 12, Table S1), no muscle could exert an estimated force greater than body weight. Five could exert a force greater than half of body weight: the tensor fasciae latae (TFL, 67\%), gluteus superficialis (GSP, 65\%), the rectus femoris (RF, 59\%), semimembranosus (SM, 56\%) and gluteus medius (GMD, 51\%). In the adult $C$. simum (Fig. 12, Table S1), no muscle could exert a force greater than $50 \%$ of body weight; the strongest muscle was the flexor digitorum profundus (FDPH, 45\%). On average, the muscles of the hindlimb of the adult $R$. unicornis had a greater normalized Fmax than those of the adult $C$. simum $(\mathrm{t}=2.33, \mathrm{p}<0.05)$.

Six muscles could exert an estimated force greater than body weight in the neonate $R$. unicornis (Fig. 12, Table S1). Those were the adductores (174\%), illiacus (150\%), flexor digitorum profundus (FDSH, 146\%), gluteobiceps (GB, 131\%), gluteus superficialis (GSP, $116 \%$ ) and tensor fasciae latae (TFL, 108\%). In the neonate C. simum (Fig. 12, Table S1), the strongest muscles were the flexores digitorum (FD, 161\%), gluteobiceps (GB, 150\%), gluteus medius (GMD, 117\%) and gracilis (GRC, 103\%). The flexor digitorum superficialis and flexor digitorum profundus were not yet separated in the neonate C. simum and were thus measured as one. There was no statistical difference in average normalized Fmax between the neonate

Peer) reviewing PDF | (2021:01:57069:2:1:NEW 29 Mar 2021) 
738 specimens of the two species $(\mathrm{t}=0.98, \mathrm{p}=0.34)$. Neonate individuals again had a greater

739 average normalized Fmax than the adults of the corresponding species $(\mathrm{t}=-5.46$ for $C$. simum, $\mathrm{t}$ $740=-4.57$ for $R$. unicornis, $\mathrm{p}<0.001$ for both species). This was true of all the individual muscles,

741 except the gluteus medius (GMD) and semimembranosus (SM) in R. unicornis, and the obturator 742 et gemelli (OG) in C. simum.

743

744 In the hindlimb, the muscles with the relatively longest fascicles generally were the

745 muscles of the thigh, except the pectineus (PTN) and the tensor fasciae latae (TFL, Fig. 13). The 746 gluteus superficialis (GSP) and the gluteus medialis (GMD) had a normalized AFL longer than

747 the gluteus profundus (GPF). The muscles of the leg all had a particularly short normalized AFL, 748 except for the tibialis cranialis (TCR) and the extensor digitorum longus (EDLo). 


\section{Discussion}

751

752

753

754

755

756

757

758

759

760

761

762

763

764

765

766

767

768

769

770

771

772

773

774

775

776

777

778

779

780

781

782

783

784

785

786

787

788

789

In the first section of the Discussion, we discuss the morphofunctional importance of the differences of qualitative myology observed between the various clades in the previous section, and draw conclusions on the relevance of the concept of graviportality from a muscular point of view. The second section is devoted to quantitative architecture and potential adaptations to sustain and move an important body mass, comparing with quantitative data for horses and tapirs. Additional quantitative comparisons were made with the muscle mass reported in $R$. unicornis by Haughton (1867), in supplementary data (Table S2, File S2). The third section presents the ontological trends that may be present in our sample.

\section{General morphological considerations}

From a qualitative point of view, we found few differences between the limb myology of R. unicornis and C. simum. No differences were found that could be obviously linked to their differences in general morphology or habitat. It seems that their large adult body mass drives most of the adaptations found in rhinoceroses' myology. Rhinos present a very similar organization of the limb muscles to the other perissodactyls, pointing at many characteristics inherited from a common ancestor (e.g. the omotransversarius inserting at least partly on the humerus, a single-headed subscapularis, the absence or great reduction of the tibialis caudalis and of the soleus). Many of the traits observed in rhinos can be linked to their high degree of cursoriality for their size. The omotransversarius and brachiocephalicus present similar paths and myology, being non-pennate with very long fascicles (Fig. 11, Table S1). This could increase the speed and working range of contraction, and permit efficient protraction of the forelimb during swing phase. The more distal insertion of the omotransversarius compared to that of horses and tapirs, on the humerus, would allow it to act with a greater lever arm on the whole limb, which may be useful to protract a relatively heavy forelimb at the cost of a slower speed of rotation. The illiacus and psoas major are the main muscles involved in protraction of the hindlimb, and present a similar organization to their forelimb counterparts, with long fascicles but a relatively low PCSA, as they only act on the limb and not on the whole animal beyond the pelvis. Mallet et al. (2019) noted that the lesser trochanter is more distal in rhinoceroses than in horses, giving the illiacus and psoas major a greater lever arm for limb protraction, similar to the humeral insertion of the omotransversarius; thus the protractors of both limbs present similar adaptations in terms of architecture and insertion. This is not found in hippopotamuses and elephants, indicating that this is likely an adaptation to both heavy weight and high speed. Overall, the propulsor muscles of the hindlimb, especially the gluteal muscles, the gluteobiceps and the semitendinosus present many similarities with the other perissodactyls. This is likely an organisation retained from a cursorial common ancestor, meaning that propulsion of the body by the hindlimb is likely conducted in a similar way in all perissodactyls. Compared to other perissodactyls, the more distal insertion of the subclavius in the forelimb, and

Peer) reviewing PDF | (2021:01:57069:2:1:NEW 29 Mar 2021) 
790

791

792

793

794

795

796

797

798

799

800

801

802

803

804

805

806

807

808

809

810

811

812

813

814

815

816

817

818

819

820

821

822

823

824

825

826

827

828

of the adductores in the hindlimb, likely give those muscles a stronger lever arm to adduct their respective limb.

In contrast, contrary to our hypothesis that rhinos would share significant traits with elephants and hippopotamuses as well, very few convergences were identified between the three clades defined as graviportal. The main one is the unique insertion of the supraspinatus muscle, on the greater tubercle of the humerus, also shared with suids and giraffes. The latter also reach a large adult body mass (up to $1930 \mathrm{~kg}$ for males, Skinner \& Mitchell, 2011). Because the supraspinatus is one of the most important extensors of the shoulder, perhaps a unique, stronger insertion on the humerus concentrates the force generated on an efficient point for shoulder extension, allowing for a greater extension capacity in heavy species. A double insertion on both tuberosities, on the other hand, could allow more shoulder stability for lighter, more cursorial species such as horses and bovids. Another characteristic common to heavy mammals seems to be a strong tensor fasciae latae. This could provide a forceful extension of the knee, although in the absence of true quantitative characterisation of Hippopotamus and elephant hindlimb muscles, this remains hypothetical. Our results indicate that from a myological point of view, rhinos, elephants and hippos can hardly be classified together as graviportal. This is especially true considering that rhinos do not show the more columnar limbs and the absence of a galloping gait generally thought to be characteristic of graviportality (Gregory, 1912; Alexander \& Pond, 1992; Mallet et al., 2019). It seems that the mammalian musculoskeletal system adapted to heavy body weight with fundamentally different paths, the set of adaptations displayed varying depending on the phylogenetic history of the clade and on the other constraints on which it may be submitted (e.g. cursoriality for rhinoceroses or semi-aquatic lifestyle for Hippopotamus).

Most muscles involved in distal limb supination and pronation are absent or greatly reduced in rhinos. This is similar to what is generally observed in ungulates, as active muscledriven pronation and supination are more restricted than in carnivores, primates, or in placental mammals ancestrally (Iwaniuk \& Whislaw, 2000; Andersson \& Werdelin, 2003; Polly, 2008; Bonnan et al., 2016). Indeed, ungulate forelimbs are almost exclusively used for locomotion, and thus are expected to be specialized in that way. Other mammals may use their forelimbs for various tasks (e.g. prey capture, grasping) that require a greater range of pronation and supination.

Several myological traits seem to present significant intraspecific variability in the species we studied (e.g. insertion of the gluteus superficialis on the fibula, presence of a vastus intermedius). Muscular architecture is also likely to vary greatly from one specimen of the same species to another. Our sample size sadly prevents us from further addressing the question of intraspecific variability. Rhinoceroses being rare and heavy animals, the preservation and transport of their body alone is a challenge making it extremely difficult to get specimens to 
829 dissect. Likewise, all specimens were captive-bred, which may have led to alterations of their 830 muscles.

831

832

833

834

\section{Architectural adaptations to weight-bearing}

835

836

$\underline{\text { Forelimb }}$

837

In rhinos, the strongest muscles are clearly the more proximal ones in the limb (Table 4). In

838 adults, the total PCSA of the muscles of the forearm is approximately $45 \%$ of that of the extrinsic

839 muscles, whereas it is $85 \%$ in horses (Table 4). Most of the muscles used by rhinos to sustain their large body mass are therefore located in the proximal region. This has a double advantage: first, it allows the muscles to grow larger in volume due to the greater space available in the proximal limb and the trunk. Second, it concentrates muscular mass in the proximal segments of the limb, avoiding having heavier distal segments which, by lever effect, would be harder to move than the proximal segments for a given mass (Alexander, 1977; Payne et al., 2005; Smith et al., 2006, 2007).

845

The serrati ventrales are particularly strong in rhinoceroses, reflecting the fact that they are the main muscles supporting the thorax between the limbs. An interesting difference between horses and rhinos is the relative PCSA of the serrati ventrales thoracis and cervicis. The latter is eight times as forceful as the former in horses, suggesting that horses have a need for an important serrati ventrales thoracis to support their thorax, but do not need an equally important serrati ventrales cervicis to support their heads. In rhinos, the two muscles have an equivalent PCSA. This is likely because rhinos have a more massive head than horses, necessitating a proportionally stronger serrati ventrales cervicis to sustain it. Additionally, rhinos, especially $C$. simum, carry their head very low with regard to the axis of the vertebral column, contrary to horses. Horses may therefore use their rhomboideus cervicis more than their serrati ventrales cervicis for supporting their head. The rhomboideus is indeed proportionally weaker in our adult $C$. simum than in horses. We sadly could not measure the rhomboideus in $R$. unicornis. The average fascicle length and pennation angle of both serrati ventrales is similar in rhinos (Figs. 11; Table S1), whereas in horses the cervicis has ten times longer fascicles than theracis. Payne, Veenman \& Wilson (2005) noted a particular architecture of the serrati ventrales thoracis in horses, with a $45^{\circ}$ angle of pennation and $4.9 \mathrm{~cm}$-long fascicles. It is remarkable that we found very similar values in our adult $R$. unicornis $\left(44^{\circ}, 4 \mathrm{~cm}\right)$, with $C$. simum presenting even shorter fascicles $\left(31^{\circ}, 1 \mathrm{~cm}\right)$. They hypothesized that this architecture improves resistance to gravity, by increasing muscle force output at the expense of range of motion. Our results are consistent with this hypothesis: the serrati ventrales thoracis seems to be specialized in supporting the massive trunk of rhinoceroses, and its action in protraction of the limb seems greatly reduced, but passed ventrales cervicis seems specialized in a similar way to support the heavy head. The latissimus 
869 dorsi is strong compared with that of horses. When the forelimb is in stance phase, its main 870 function is to support and decelerate the body; its greater PCSA is likely necessary given the 871 greater body mass of rhinos.

872

873

874

875

876

877

878

879

880

881

882

883

884

885

886

887

888

889

890

891

892

893

894

895

896

897

898

899

900

901

902

903

904

905

906

907

908
The infraspinatus and supraspinatus are the strongest muscles in the shoulder region, reflecting their important actions in extension and stabilization of this articulation. Those muscles, as well as the subscapularis, present noticeably short fascicles, suggesting that they are specialized in generating a strong force but only producing a small displacement of the joint. Their action is most likely to lock the shoulder joint firmly into place (i.e. acting as stabilizers; or resisting flexion under gravity). The biceps brachii is also a strong muscle with short fascicles, which is likely due to its action in shoulder flexion, rather than its action as a flexor of the forearm. The biceps may also be important in the protraction of the limb during the initiation of the swing phase, as in horses where it stores elastic energy during the stance phase that it can then recover with less metabolic cost for the animal (Watson \& Wilson, 2007). This is consistent with the prior observation that the insertion area of the biceps brachii on the radius is more robust in the heaviest species of rhinos (Mallet et al., 2019). The triceps brachii, especially its caput longum, is also among the strongest muscles, and benefits from a long olecranon in rhinoceroses, creating a large lever arm (Maynard Smith \& Savage, 1956; Mallet et al., 2019). Its fascicles are longer than those of the biceps and the extensors and stabilizers of the shoulder, likely related to the length of the olecranon, balancing length change costs and benefits from fascicle lengths and lever arms (Gans \& De Vree, 1987). The triceps brachii's combined actions with the biceps, the infraspinatus, and the supraspinatus are probably of great importance to support the limb against gravity. Of similar actions are the pectorales, as their large maximal force output should help maintain the limb in adduction; the more distal insertion of the subclavius, on the humerus rather than the scapula, may provide this muscle with a greater lever arm in this regard. Mallet et al. (2019) noted a substantial development of the lesser tubercle in heavy rhinos (including our two species), and inferred from horses that this was due to the medial insertion of the supraspinatus. That insertion is absent in rhinoceroses; the distinct development of this region may instead be linked to the considerable forces imposed by the combined pectoralis ascendens and subclavius.

The pattern observed in the muscles of the forearm is similar to that of horses and tapirs. The flexores digitorum are the strongest muscles, generally followed by the ulnaris lateralis and the flexor carpi ulnaris. In horses, all of those muscles act in synergy to initiate the stance phase and decelerate the body; it is likely that their role is the same in rhinos (Harrison et al., 2010). The extensor digitorum communis and lateralis and the extensor carpi radialis are stronger in rhinos than in tapirs and horses. These muscles are involved in the stability of all the articulations of the manus; it is therefore logical that they have to be proportionally stronger in heavier animals. The tendons of all the muscles inserting on the digits are generally of similar length and apparent robustness for all three digits, which is concordant with the tridactyly of

Peer] reviewing PDF | (2021:01:57069:2:1:NEW 29 Mar 2021) 
909 rhinoceroses and that forces are evenly distributed between the toes (Panagiotopoulou, Pataky \& 910 Hutchinson, 2019).

911

912

913

914

915

916

917

918

919

920

921

922

923

924

925

926

927

928

929

930

931

932

933

934

935

936

937

938

939

940

941

942

943

944

945

946

947

948

This general specialization of the forelimb for body weight support is consistent with what is generally known in quadrupedal mammals and especially ungulates, and is here taken to another extreme by the heavy weight of rhinoceroses. The muscles of the forelimb had a total PCSA higher than those of the hindlimb in all our specimens, whereas in highly cursorial horses, the hindlimb has a higher total PCSA than the forelimb, although PCSA data are absent for four muscles of the horse forelimb (Tables 4, 5). All of these inferences are consistent with the higher degree of integration linked to mass observed between the bones of the forelimb in rhinoceroses, compared to those of the hindlimb (Mallet et al., 2020). The large PCSA shown by the muscles of the forelimb, required for body support, may drive the bones' shape towards similar adaptations (e.g. larger insertion areas) and thus increase the degree of integration between them.

\section{$\underline{\text { Hindlimb }}$}

The average PCSA of the muscles remained roughly constant in the different segments of the hindlimb (Table 5). This is in stark contrast with E. caballus, where the muscles of the leg confer greater forces, on average, than the muscles of the pelvis, which is consistent with the pattern observed in the forelimb. This considerable force-generating capacity of the equine distal hindlimb is driven by the flexores digitorum, which have a combined PCSA of $1120 \mathrm{~cm}^{2}$, which is much stronger than what is observed for any other muscles in horses or rhinoceroses. Overall, our adult $R$. unicornis had a total PCSA in the hindlimb equivalent to that of horses, and $C$. simum's PCSA was $60 \%$ of that of horses, despite horses being four times lighter than both our specimens. This is most likely due to the high degree of cursorial specialization observed in horses, further exacerbated by domestication. Most of the horses dissected in Payne et al. (2005) are indeed from breeds used for horse racing, capable of reaching up to $19 \mathrm{~m} \mathrm{~s}^{-1}$ with a rider on (Spence et al., 2012) whereas C. simum might reach $\sim 7.5 \mathrm{~m} \mathrm{~s}^{-1}$ (Alexander \& Pond, 1992); no empirical data are available for R. unicornis. Additionally, our individual of C. simum had a generalized weakness at the end of its life, which may have lowered its muscular mass and thus PCSA. This may also explain why it had a lower normalized Fmax than our adult $R$. unicornis in the hindlimb. The forelimb might not have been affected because its weight-bearing role is likely more obligatorily required for a captive animal than the propulsor role of the hindlimb, which may have prevented muscle atrophy, but this is speculative.

The strongest muscles in the hindlimb are those involved in gravitational support and propulsion of the body, i.e. the gluteal muscles, the gluteobiceps, semimembranosus, semitendinosus, quadriceps femoris, as well as the gastrocnemius and flexores digitorum. An interesting difference from the horse is the greater PCSA of the gluteus superficialis, which is even larger than that of the medius in both our R. unicornis. When the hip is already partially in

Peer) reviewing PDF | (2021:01:57069:2:1:NEW 29 Mar 2021) 
949 extension due to the action of the hamstring muscles and of the gluteus medius, the gluteus

950

951

952

953

954

955

956

957

958

959

960

961

962

963

964

965

966

967

968

969

970

971

972

973

974

975

976

977

978

979

980

981

982

983

984

985

986

987

988

superficialis could act as an additional extensor of the limb, and benefit from a longer lever arm than the gluteus medius, incurred by the more distal position of the third trochanter compared to the greater trochanter. Mallet et al. (2019) reported that in R. unicornis, those two trochanters are sometimes linked by a bony bridge, although this was not the case in our specimens. There could therefore be a continuity in the insertion of all the gluteal muscles, and the superficialis could act as an extensor after the more proximal medius and profundus have already partially extended the hip, perhaps explaining why its normalized Fmax is greater in our R. unicornis specimens. This shift of action of the gluteus medius towards that of the gluteus superficialis would explain the reduction in the proximal development of the greater trochanter in heavy rhinos noted by Mallet et al. (2019).

As in horses, the gluteobiceps, semitendinosus and semimembranosus of our rhinos were all strong muscles, and yet retained relatively long fascicles. This likely reflects a tradeoff between being able to produce a large amount of force and being able to contract rapidly and over a longer distance (Payne et al., 2005). Those muscles would therefore be capable of producing a large amount of work useful for body propulsion at a relatively fast speed. This is also the case for the different heads of the quadriceps femoris, although their fascicles are slightly shorter, indicating a less extreme potential range and speed of motion at the knee than at the hip. The tensor fasciae latae has shorter fascicles and is therefore likely to serve as an antigravity muscle keeping the knee in extension.

The strong gastrocnemius and flexores digitorum profundus are highly pennate, with long tendons able to store elastic strain energy, an architecture that is not observed in elephants (Weissengruber \& Forstenpointner, 2004), which do not gallop or trot. This is consistent with the observation that the tuber calcanei remains relatively elongated in rhinos but is shortened in elephants (Etienne et al., 2020). In horses, the flexores digitorum are four times as strong as the gastrocnemius, whereas in both our adult rhinos, the flexores digitorum are only 1.6 as strong as the gastrocnemius. This may be because the gastrocnemius inserts on the tuber calcanei, a large lever arm. It is thus more capable of acting against gravity than the flexores digitorum, perhaps avoiding hyperextension of the ankle, useful for heavy animals like rhinos.

Despite those exceptions most likely linked to the large body mass of rhinos, the pattern observed in the hindlimb in terms of relative PCSA and fascicle length is similar to that of horses (Payne et al., 2005, Crook et al., 2008). This is consistent with the expectation that the hindlimbs perform a major function in body propulsion, as well as a lesser role in support relative to the forelimbs. Comparisons with quantitative anatomical and functional data for elephants and hippopotamuses would be interesting to determine if these animals that do not gallop present a different pattern.

Peer] reviewing PDF | (2021:01:57069:2:1:NEW 29 Mar 2021) 


\section{Ontogeny}

990

991 Our adult specimens were approximately 40 times heavier than our neonates. Several

992 ontogenetic trends could be observed in our sample, although limitations of sample size in this

993 study prevent us from doing a true scaling analysis to quantify how muscles grow in

994 rhinoceroses; a cross-sectional population-level study would be necessary for this. The relative

995 maximal isometric force (Fmax) of almost all muscles suggested a negatively allometric scaling

996 relationship (Fig. 14); i.e. the neonates were able to exert a much greater normalized Fmax than

997 the adults. This is consistent with our initial hypothesis: in general, smaller mammals are

998 expected to have greater Fmax for their size, especially for muscles involved in locomotion

999 (Carrier, 1995, 1996; Herrel \& Gibb, 2006). Weight is expected to scale with linear dimensions

1000 cubed whereas PCSA, as an area, scales with linear dimensions squared (Hildebrand, 1982;

1001 Hildebrand et al., 1985; Biewener, 1989) and thus strength : weight ratios inevitably decline in

1002 large animals via ontogeny or phylogeny. On average, normalized Fmax is 4.38 times greater in

1003 the neonate $R$. unicornis than in the adult, and 8.16 times greater in $C$. simum. Again, this

1004 difference could be due to the general weakness our adult $C$. simum suffered at the end of its life,

1005 or to differences in the term of the pregnancy of the neonates that could affect muscle

1006 development. A few muscles were an exception to the negatively allometricscaling we inferred:

1007 the supraspinatus, flexor digitorum superficialis of the forelimb, gluteus medius and

1008 semimembranosus in R. unicornis, and the serrati ventrales, flexor digitorum profundus of the

1009 forelimb and obturator et gemelli in $C$. simum. Except the obturator et gemelli, they were all

1010 strong muscles involved in either body support or fore/aft motion. This indicates that those

1011 muscles probably develop their large Fmax during the growth of the animal and had not yet had

1012 the opportunity to do so in very young individuals. Conversely, muscles that have extremely high

1013 normalized Fmax in the neonates compared to the adults may start with a relatively high Fmax

1014 due to phylogenetic or developmental constraints and then undergo a reduction of muscle

1015 volume due to being underused. This is likely the case of the extensor carpi obliquus and the

1016 triceps longus caput mediale.

1017

1018 


\section{Conclusions}

1020

1021

1022

1023

1024

1025

1026

1027

1028

1029

1030

1031

1032

1033

1034

1035

1036

1037

1038

1039

1040

1041

1042

1043

1044

1045

1046

1047

1048

1049

1050

1051

1052

1053

1054
Our study has clarified the appendicular musculature of a clade that was in dire need of a reassessment, and provides the first detailed quantification of muscular architecture for such giant animals. Overall, from a qualitative point of view and contrary to our hypothesis, rhinoceroses' limb musculature presents only a few characteristics linking them with elephants and hippopotamuses, and is instead similar to that of the other perissodactyls, as phylogenetic relationships would predict. In accordance with our hypothesis, rhinos present similar adaptations to running as equids and tapirs do, although with adjustments that probably compensate for their greater body mass, such as more distal insertions for the protractor and adductor muscles. In terms of quantitative architecture, adaptations to heavy weight include stronger forelimb than hindlimb muscles, reflecting the greater emphasis on weight-bearing in the forelimbs of most mammalian quadrupeds. As in most tetrapods, to varying degrees, muscle mass and therefore maximal isometric force are concentrated in the proximal part of both limbs, thus decreasing the mass of the distal segments. Some extensor muscles, mainly in the forelimb (e.g. serrati ventrales, supraspinatus, infraspinatus, biceps brachii) display remarkably short fibers and high degrees of pennation that help them to generate strong forces, useful for gravitational support and joint stabilization. Other muscles present longer fascicles and thus a greater speed and working range, but still possess a greater estimated maximal isometric force due to their large volume. Those are mainly propulsor muscles of the hindlimb (e.g. gluteal muscles, gluteobiceps, quadriceps femoris). Ontogenetic scaling of maximal isometric force is evident in our individuals, with neonates exhibiting a much higher normalized Fmax than adults in almost every muscle. Some extensor muscles are an exception, which indicates that they likely develop their great strength during the growth of the animal. Our results indicates that rhinos, hippos and elephants can hardly be classified together as 'graviportal' from a muscular point of view. It rather seems that they have evolved several traits, in terms of musculoskeletal adaptations (e.g., more distal insertion of protractor and adductor muscles, relatively stronger forelimb for body support and braking during locomotion), to adapt to supporting and moving a body mass of several tons without compromising on their ability to gallop and achieve somewhat fast speeds, and that these traits could not be regrouped together under the concept of graviportality. Further studies on elephants and hippopotamuses would prove especially useful to provide an even more comprehensive view of how land vertebrates adapt to sustain a heavy weight, as well as precise biomechanical modelling of the musculoskeletal systems of heavy taxa. 
1055

1056

1057

1058

1059

1060

1061

1062

1063

1064

1065

1066

1067

1068

1069

1070

1071

1072

1073

1074

1075

1076

1077

1078

1079

1080

1081

1082

1083

1084

1085

1086

1087

1088

1089

1090

1091

1092

1093

1094

\section{Acknowledgements}

We wish to acknowledge very warmly Suzannah Williams and Hinnah Rehman, undergraduates at the Royal Veterinary College who helped greatly with the dissections of the White and Indian rhinos, respectively, and with data collection. We thank Elizabeth Ferrer, Sharon Warner and all those that helped in the Structure and Motion Laboratory (RVC) for assistance in data collection during this project, along with post-mortem room support from Richard Prior. ZSL Whipsnade Zoo, Woburn Safari Park, Munich Hellabrunn Zoo and their staff are wholeheartedly thanked for generously donating the specimens used. Finally, we warmly thank Korakot Nganvongpanit (Chiang Mai University, Thailand) for editorial work, as well as Jamie MacLaren (University of Liège, Belgium) and two anonymous reviewers for their helpful comments and constructive critiques.

\section{References}

Alexander RM. 1974. The mechanics of jumping by a dog (Canis familiaris). Journal of Zoology 173:549-573. DOI: 10.1111/j.1469-7998.1974.tb04134.x.

Alexander RM. 1977. Allometry of the limbs of antelopes (Bovidae). Journal of Zoology 183:125-146. DOI: https://doi.org/10.1111/j.1469-7998.1977.tb04177.x.

Alexander R. 1985. Body Support, Scaling, and Allometry. In: Hildebrand M, Bramble DM, Liem KF, Wake D eds. Functional Vertebrate Morphology. Cambridge, USA: Belknap Press of Harvard University Press, 26-37.

Alexander RM, Pond C. 1992. Locomotion and bone strength of the White Rhinoceros, Ceratotherium simum. Journal of Zoology 227:63-69. DOI: 10.1111/j.14697998.1992.tb04344.x.

Anderson K, Werdelin L. 2003. The evolution of cursorial carnivores in the Tertiary: implications of elbow-joint morphology. Proceedings of the Royal Society B: Biological Sciences 270:S165-S165. DOI: https://doi.org/10.1098/rsbl.2003.0070

Azizi E, Brainerd EL, Roberts TJ. 2008. Variable gearing in pennate muscles. Proceedings of the National Academy of Sciences 105:1745-1750. DOI: 10.1073/pnas.0709212105.

Barone R. 1999. Anatomie comparée des mammifères domestiques. Tome 1: ostéologie. Paris: Vigot Frères.

Barone R. 2010. Anatomie comparée des mammifères domestiques. Tome $2:$ arthrologie et myologie. Paris: Vigot Frères.

Becker D. 2003. Paléoécologie et paléoclimats de la Molasse du Jura (Oligo-Miocène): apport des Rhinocerotoidea (Mammalia) et des minéraux argileux. Doctoral Dissertation Thesis, Université de Fribourg.

Becker D, Bürgin T, Oberli U, Scherler L. 2009. Diaceratherium lemanense (Rhinocerotidae) from Eschenbach (eastern Switzerland): systematics, palaeoecology, palaeobiogeography. Neues Jahrbuch für Geologie und Paläontologie - Abhandlungen 254:5-39. DOI: 10.1127/0077-7749/2009/0002. 
1095

1096

1097

1098

1099

1100

1101

1102

1103

1104

1105

1106

1107

1108

1109

1110

1111

1112

1113

1114

1115

1116

1117

1118

1119

1120

1121

1122

1123

1124

1125

1126

1127

1128

1129

1130

1131

1132

1133

1134

Beddard FE, Treves F. 1889. On the Anatomy of Rhinoceros sumatrensis. Proceedings of the Zoological Society of London 57:7-25. DOI: 10.1111/j.1469-7998.1889.tb06740.x.

Biewener AA. 1989. Mammalian Terrestrial Locomotion and Size. BioScience 39:776-783. DOI: $10.2307 / 1311183$.

Biewener AA. 1990. Biomechanics of mammalian terrestrial locomotion. Science 250:10971103. DOI: $10.1126 /$ science. 2251499.

Biewener AA. 2005. Biomechanical consequences of scaling. Journal of Experimental Biology 208:1665-1676. DOI: 10.1242/jeb.01520.

Biewener AA, Patek S. 2018. Animal Locomotion. New York: Oxford University Press.

Bonnan MF, Shulman J, Varadharajan R, Gilbert C, Wilkes M, Horner A, Brainerd, EL. 2016. Forelimb kinematics of rats using XROMM, with implications for small eutherians and their fossil relatives. PLoS ONE 11: e0149377. DOI: https://doi.org/10.1371/journal.pone.0149377

Borges DCS, Pereira SG, de Souza RR, da Silva JOR, Santos ALQ. 2016. Anatomia óssea e muscular da coxa de Tapirus terrestris (Perissodactyla, Taperidae). Revista Brasileira de Ciência Veterinária 25: 42-48.

Bressou C. 1961. La myologie du tapir (Tapirus indicus L.). Mammalia 25:358-400. DOI: 10.1515/mamm.1961.25.3.358.

Brown NA, Kawcak CE, McIlwraith CW, Pandy MG. 2003. Architectural properties of distal forelimb muscles in horses, Equus caballus. Journal of Morphology 258:106-114.

Campbell B. 1936. The comparative myology of the forelimb of the hippopotamus, pig and tapir. American Journal of Anatomy 59:201-247. DOI: 10.1002/aja.1000590203.

Carrier DR. 1995. Ontogeny of jumping performance in the black-tailed jackrabbit (Lepus californicus). Zoology 94:309-313.

Carrier DR. 1996. Ontogenetic limits on locomotor performance. Physiological Zoology 69:467488.

Christiansen P, Paul GS. 2001. Limb bone scaling, limb proportions, and bone strength in neoceratopsian dinosaurs. Gaia 16:13-29.

Coombs WP. 1978. Theoretical Aspects of Cursorial Adaptations in Dinosaurs. The Quarterly Review of Biology 53:393-418.

de Courcy C. 2010.Zoology: Trevelyan's rhinoceros and other gifts from India to Dublin Zoo. Available at https://www.historyireland.com/18th-19th-century-history/zoologytrevelyansrhinoceros-and-other-gifts-from-india-to-dublin-zoo/ (accessed October 7, 2020).

Crook TC, Cruickshank SE, McGowan CM, Stubbs N, Wakeling JM, Wilson AM, Payne RC. 2008. Comparative anatomy and muscle architecture of selected hind limb muscles in the Quarter Horse and Arab. Journal of Anatomy 212:144-152. DOI: 10.1111/j.14697580.2007.00848.x.

Cuff AR, Sparkes EL, Randau M, Pierce SE, Kitchener AC, Goswami A, Hutchinson JR. 2016. The scaling of postcranial muscles in cats (Felidae) I: forelimb, cervical, and thoracic muscles. Journal of Anatomy 229:128-141. DOI: 10.1111/joa.12477.

Dagg AI. 1973. Gaits in mammals. Mammal Rev 3:135-154.

Peer) reviewing PDF | (2021:01:57069:2:1:NEW 29 Mar 2021) 
1135 Dinerstein E. 2011. Family Rhinocerotidae (Rhinoceroses). In: Wilson DE, Mittermeier RA eds.

1136

1137

1138

1139

1140

1141

1142

1143

1144

1145

1146

1147

1148

1149

1150

1151

1152

1153

1154

1155

1156

1157

1158

1159

1160

1161

1162

1163

1164

1165

1166

1167

1168

1169

1170

1171

1172

1173

\section{Handbook of the Mammals of the World. Volume 2: Hoofed Mammals. Barcelona: Lynx} Edicions, 144-181.

Dutto DJ, Hoyt DF, Clayton HM, Cogger EA, Wickler SJ. 2006. Joint work and power for both the forelimb and hindlimb during trotting in the horse. Journal of Experimental Biology 209:3990-3999. DOI: 10.1242/jeb.02471.

Eales NB. 1926. The Anatomy of the head of a fœtal African elephant, Elephas africanus (Loxodonta africana). Transactions of the Royal Society of Edinburgh 54:491-551.Eales NB. 1928. The Anatomy of a fetal African elephant, Elephas africanus (Loxodonta africana). Part II. The Body Muscles. Transactions of the Royal Society of Edinburgh 55:609-642.

Eisenmann V, Guérin C. 1984. Morphologie fonctionnelle et environnement chez les périssodactyles. Geobios 17:69-74. DOI: 10.1016/S0016-6995(84)80158-8.

Etienne C, Mallet C, Cornette R, Houssaye A. 2020. Influence of mass on tarsus shape variation: a morphometrical investigation among Rhinocerotidae (Mammalia: Perissodactyla).

Biological Journal of the Linnean Society 129:950-974. DOI: 10.1093/biolinnean/blaa005.

Fisher RE, Scott KM, Adrian B. 2010. Hind limb myology of the common hippopotamus, Hippopotamus amphibius (Artiodactyla: Hippopotamidae). Zoological Journal of the Linnean Society 158:661-682. DOI: 10.1111/j.1096-3642.2009.00558.x.

Fisher RE, Scott KM, Naples VL. 2007. Forelimb myology of the pygmy hippopotamus (Choeropsis liberiensis). The Anatomical Record 290:673-693. DOI: 10.1002/ar.20531.

Foose TJ, Khan MK bin M, Strien NJ van. 1997. Asian rhinos : status survey and conservation action plan. Gland: IUCN.

Gans C, Gaunt AS. 1991. Muscle architecture in relation to function. Journal of Biomechanics 24 Suppl 1:53-65. DOI: 10.1016/0021-9290(91)90377-y.

Gans C, de Vree F. 1987. Functional bases of fiber length and angulation in muscle. Journal of Morphology 192:63-85. DOI: 10.1002/jmor.1051920106.

Garland T. 1983. The relation between maximal running speed and body mass in terrestrial mammals. Journal of Zoology 199:157-170. DOI: 10.1111/j.1469-7998.1983.tb02087.x.

Gould FD. 2017. Testing the role of cursorial specializations as adaptive key innovations in Paleocene-Eocene ungulates of North America. Journal of Mammalian Evolution 24:453463.

Gratiolet P-L, Alix E. 1867. Recherches sur l'anatomie de l'hippopotame. Paris.

Gregory WK. 1912. Notes on the principles of quadrupedal locomotion and on the mechanism of the limbs in hoofed animals. Annals of the New York Academy of Sciences 22:267-294. DOI: 10.1111/j.1749-6632.1912.tb55164.x.

Guérin C. 1980. Les rhinocéros (Mammalia, Perissodactyla) du Miocène terminal au Pléistocène supérieur en Europe occidentale: comparaison avec les espèces actuelles. Documents $d u$ Laboratoire de Géologie de la Faculté des Sciences de Lyon 79:1-1182.

Peer) reviewing PDF | (2021:01:57069:2:1:NEW 29 Mar 2021) 
1174 Harrison, S. M., Whitton, R. C., Kawcak, C. E., Stover, S. M., \& Pandy, M. G. 2010.

1175

1176

1177

1178

1179

1180

1181

1182

1183

1184

1185

1186

1187

1188

1189

1190

1191

1192

1193

1194

1195

1196

1197

1198

1199

1200

1201

1202

1203

1204

1205

1206

1207

1208

1209

1210

1211

1212

1213

Relationship between muscle forces, joint loading and utilization of elastic strain energy in equine locomotion. Journal of Experimental Biology 213:3998-4009.

Haughton S. 1867. On the muscular anatomy of the rhinoceros. Proceedings of the Royal Irish Academy 9:515-526.

Herr HM, Huang GT, McMahon TA. 2002. A model of scale effects in mammalian quadrupedal running. Journal of Experimental Biology 205:959-967.

Herrel A, Gibb AC. 2006. Ontogeny of performance in vertebrates. Physiological and Biochemical Zoology 79:1-6.

Hildebrand M. 1982. Analysis of Vertebrate Structure. New York: Wiley.

Hildebrand M, Bramble DM, Liem KF, Wake D. 1985. Functional Vertebrate Morphology. Cambridge, USA: Belknap Press of Harvard University Press.

Iwaniuk AN, Whishaw, IQ. 2000. On the origin of skilled forelimb movements. Trends in Neurosciences 23:372-376. DOI: https://doi.org/10.1016/S0166-2236(00)01618-0

Lieber RL, Ward SR. 2011. Skeletal muscle design to meet functional demands. Philosophical Transactions of the Royal Society B: Biological Sciences 366:1466-1476. DOI: 10.1098/rstb.2010.0316.

Macdonald AA, Kneepkens AFLM, van Kolfschoten T, Houtekamer JL, Sondaar PY, Badoux DM. 1985. Comparative anatomy of the limb musculature of some Suina. Fortschritte der Zoologie 30:95-98.

MacLaren JA, McHorse BK. 2020. Comparative forelimb myology and muscular architecture of a juvenile Malayan tapir (Tapirus indicus). Journal of Anatomy 236:85-97. DOI: 10.1111/joa.13087.

Mallet C. 2020. Long bone morphological adaptation to graviportality in Rhinocerotoidea. Doctoral Dissertation Thesis. Paris, France: Muséum National d'Histoire Naturelle.

Mallet C, Billet G, Houssaye A, Cornette R. 2020. A first glimpse at the influence of body mass in the morphological integration of the limb long bones: an investigation in modern rhinoceroses. Journal of Anatomy 237:704-726.

Mallet C, Cornette R, Billet G, Houssaye A. 2019. Interspecific variation in the limb long bones among modern rhinoceroses — extent and drivers. PeerJ 7:e7647. DOI: 10.7717/peerj.7647.

Mariappa D. 1986. Anatomy and Histology of the Indian Elephant. Oak Park, Michigan: Indira Pub. House.

Maynard Smith J, Savage RJG. 1956. Some locomotory adaptations in mammals. Journal of the Linnean Society of London, Zoology 42:603-622. DOI: https://doi.org/10.1111/j.10963642.1956.tb02220.x.

McClearn D. 1985. Anatomy of raccoon (Procyon lotor) and coati (Nasua narica and N. nasua) forearm and leg muscles: Relations between fiber length, moment-arm length, and joint-angle excursion. Journal of Morphology 183:87-115. DOI: 10.1002/jmor.1051830106.

Mendez J, Keys A. 1960. Density of fat and bone mineral of mammalian muscle. Metabolism 9:184-188.

Peer] reviewing PDF | (2021:01:57069:2:1:NEW 29 Mar 2021) 
1214 Miall LC, Greenwood F. 1878. Anatomy of the Indian Elephant. Journal of Anatomy and 1215 Physiology 12:261-287.

1216 Murie J. 1871. The Malayan Tapir. Journal of Anatomy and Physiology 6:131-512.19.

1217 Myatt JP, Crompton RH, Payne-Davis RC, Vereecke EE, Isler K, Savage R, D’Août K, Günther 1218 MM, Thorpe SKS. 2012. Functional adaptations in the forelimb muscles of non-human great 1219 apes. Journal of Anatomy 220:13-28. DOI: 10.1111/j.1469-7580.2011.01443.x.

1220

1221

1222

1223

1224

1225

1226

1227

1228

1229

1230

1231

1232

1233

1234

1235

1236

1237

1238

1239

1240

1241

1242

1243

1244

1245

1246

1247

1248

1249

1250

1251

Nagel RM, Forstenpointner G, Soley JT, Weissengruber GE. 2018. Muscles and fascial elements of the antebrachium and manus of the African elephant (Loxodonta africana, Blumenbach 1797): starring comparative and functional considerations. Anatomia, Histologia, Embryologia 47:195-205. DOI: 10.1111/ahe.12340.

Pales L, Garcia MA. 1981. Atlas ostéologique pour servir à l'identification des mammifères du Quaternaire, 1 - Les membres. Paris: CNRS.

Panagiotopoulou O, Pataky TC, Hutchinson JR. 2019. Foot pressure distribution in White Rhinoceroses (Ceratotherium simum) during walking. PeerJ 7:e6881. DOI: 10.7717/peerj.6881.

Pandy MG. 1999. Moment arm of a muscle force. Exercise and Sport Sciences Reviews 27:79118.

Payne RC, Hutchinson JR, Robilliard JJ, Smith NC, Wilson AM. 2005. Functional specialisation of pelvic limb anatomy in horses (Equus caballus). Journal of Anatomy 206:557-574.

Payne RC, Veenman P, Wilson AM. 2005. The role of the extrinsic thoracic limb muscles in equine locomotion. Journal of Anatomy 206:193-204. DOI: 10.1111/j.14697580.2005.00353.x.

Pereira SG, Santos ALQ, Borges DCS, Ribeiro PRQ, de Souza RR. 2017. Bone and muscular anatomy of the forearm and hand in Tapirus terrestris (Perissodactyla, Tapiridae). Biotemas 30 (2): 35-41Polly D. 2008. Limbs in mammalian evolution. In: Hall, B.K. ed. Fins into limbs: evolution, development, and transformation. Chicago: University of Chicago Press, 245-268.

Powell PL, Roy RR, Kanim P, Bello MA, Edgerton VR. 1984. Predictability of skeletal muscle tension from architectural determinations in guinea pig hindlimbs. Journal of Applied Physiology: Respiratory, Environmental and Exercise Physiology 57:1715-1721. DOI: 10.1152/jappl.1984.57.6.1715.

Radinsky LB. 1966. The adaptive radiation of the phenacodontid condylarths and the origin of the Perissodactyla. Evolution 20:408-417.

Ren L, Miller CE, Lair R, Hutchinson JR. 2010. Integration of biomechanical compliance, leverage, and power in elephant limbs. Proceedings of the National Academy of Sciences 107:7078-7082. DOI: 10.1073/pnas.0911396107.

Silva M, Downing JA. 1995. Handbook of Mammalian Body Masses. Boca Raton, Florida: CRCPress. 
1252

1253

1254

1255

1256

1257

1258

1259

1260

1261

1262

1263

1264

1265

1266

1267

1268

1269

1270

1271

1272

1273

1274

1275

1276

1277

1278

1279

1280

1281

1282

1283

Skinner JD, Mitchell G. 2011. Family Giraffidae (Giraffe and Okapi). In: Wilson DE, Mittermeier RA eds. Handbook of the Mammals of the World. Volume 2: Hoofed Mammals. Barcelona: Lynx Edicions, 788-802.

Smith NC, Payne RC, Jespers KJ, Wilson AM. 2007. Muscle moment arms of pelvic limb muscles of the ostrich (Struthio camelus). Journal of Anatomy 211:313-324. DOI: 10.1111/j.1469-7580.2007.00762.x.

Smith NC, Wilson AM, Jespers KJ, Payne RC. 2006. Muscle architecture and functional anatomy of the pelvic limb of the ostrich (Struthio camelus). Journal of Anatomy 209:765779. DOI: 10.1111/j.1469-7580.2006.00658.x.

Spence AJ, Thurman AS, Maher MJ, Wilson AM. 2012. Speed, pacing strategy and aerodynamic drafting in Thoroughbred horse racing. Biology Letters 8:678-681. DOI: 10.1098/rsbl.2011.1120.

Trenkwalder TH. 2013. Über die Muskulatur des Schultergürtels und der proximalen Vorderextremität des afrikanischen Elefanten (Loxodonta africana). Doctoral Dissertation Thesis. Vienna, Austria: Department of Pathobiology, Institute for Anatomy, Histology \& Embryology, University of Veterinary Medicine.

Watson J, Wilson A. 2007. Muscle architecture of biceps brachii, triceps brachii and supraspinatus in the horse. Journal of Anatomy 210:32-40. DOI: 10.1111/j.14697580.2006.00669.x.

Weissengruber GE, Forstenpointner G. 2004. Musculature of the crus and pes of the African elephant (Loxodonta africana): insight into semiplantigrade limb architecture. Anatomy and Embryology 208:451-461. DOI: 10.1007/s00429-004-0406-1.

Wilson DE, Mittermeier RA. 2011. Handbook of the Mammals of the World. Volume 2: Hoofed Mammals. Barcelona: Lynx Edicions.

Windle HCA, Parsons FG. 1902. On the Muscles of the Ungulata. Proceedings of the Zoological Society of London 71:656-704. DOI: 10.1111/j.1469-7998.1902.tb08194.x.

Witte TH, Knill K, Wilson AM. 2004. Determination of peak vertical ground reaction force from duty factor in the horse (Equus caballus). Journal of Experimental Biology 207:3639-3648.

DOI: $10.1242 /$ jeb.01182.

Woledge RC, Curtin NA, Homsher E. 1985. Energetic Aspects of Muscle Contraction. Monographs of the Physiological Society 41:1-357.

Peer] reviewing PDF | (2021:01:57069:2:1:NEW 29 Mar 2021) 


\section{Figure 1}

Diagram representing the muscles of the left forelimb and their origins and insertions, lateral view.

Normalized Fmax values are from our adult $R$. unicornis individual; muscles whose Fmax could not be determined (brachialis, extensor carpi radialis, flexor carpi ulnaris) are classified as below $20 \%$ of body weight. The skeleton image is that of $R$. sondaicus (Based on Pales \& Garcia, 1981), and is courtesy of https://www.archeozoo.org/archeozootheque/ and Michel Coutureau, under CC BY-NC-SA 4.0 license. Dashed lines represent muscles hidden by bones in lateral view. Please note that origins and insertions are not restricted to the exact points indicated by the lines.

(A) serrati ventrales thoracis (SVT) and cervicis (SVC), supraspinatus (SSP), infraspinatus (ISP), pectorales ascendens (PA), descendens and transversus (PCD + PCT), subclavius (SU), coracobrachialis (CB), triceps brachii caput longum (TLo), laterale (TL) and mediale with anconeus (TM + AN), tendon of the triceps brachii (TT), tensor fasciae antebrachiae (TFA), extensor digitorum communis (EDC) and lateralis (EDLaF), flexor carpi radialis (FCR) and ulnaris (FCU).

(B) rhomboidei (RHB), trapezius (TP), omotransversarius (OT), brachiocephalicus (BC), subscapularis (SSC), deltoideus acromialis (DLA) and scapularis (DLS), latissimus dorsi (LD), teres major (TRM), biceps brachii (BB), brachialis (BR), brachioradialis (BRA), extensor carpi radialis (ECR) and obliquus (ECO), ulnaris lateralis (UL), flexor digitorum superficialis (FDSF) and profundus (FDSP). 
A

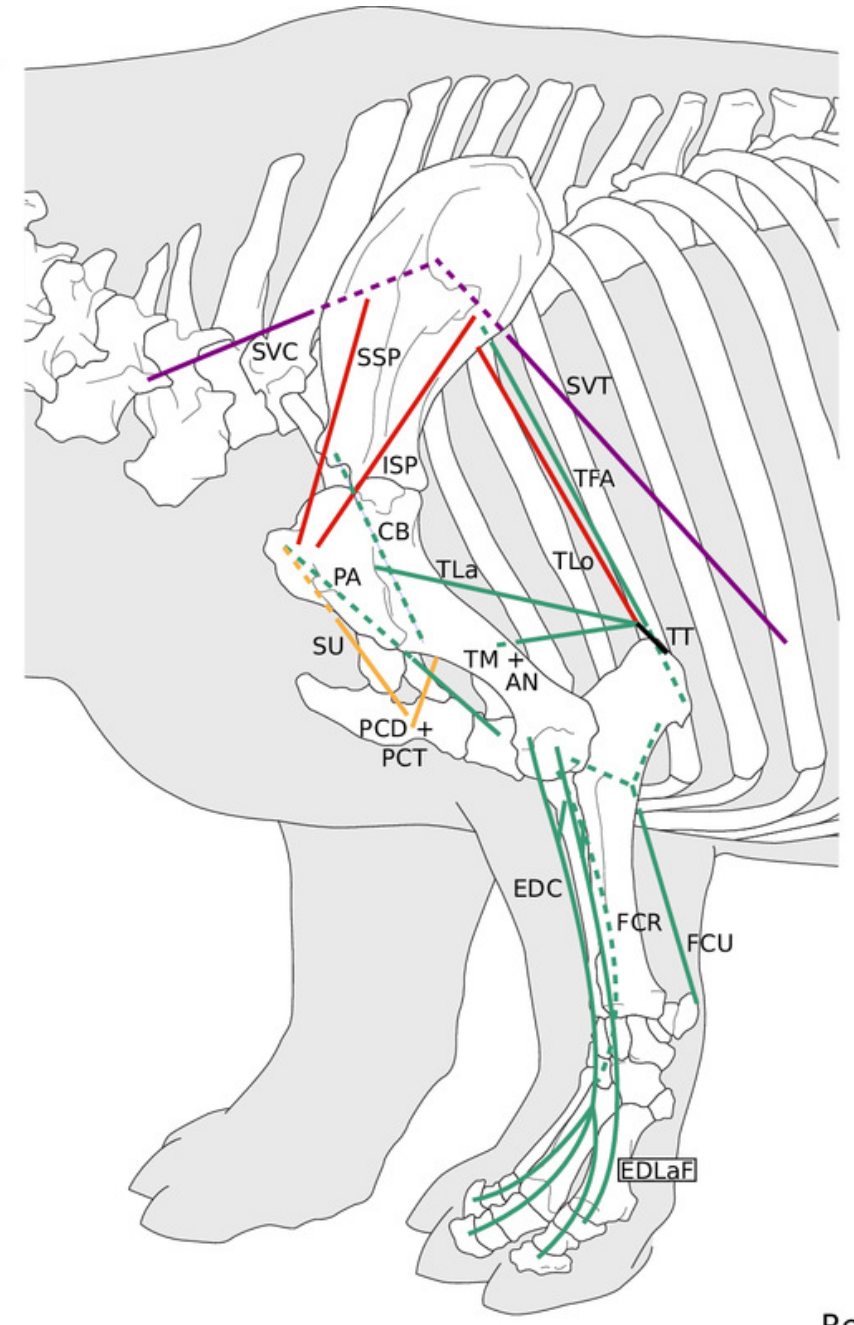

B

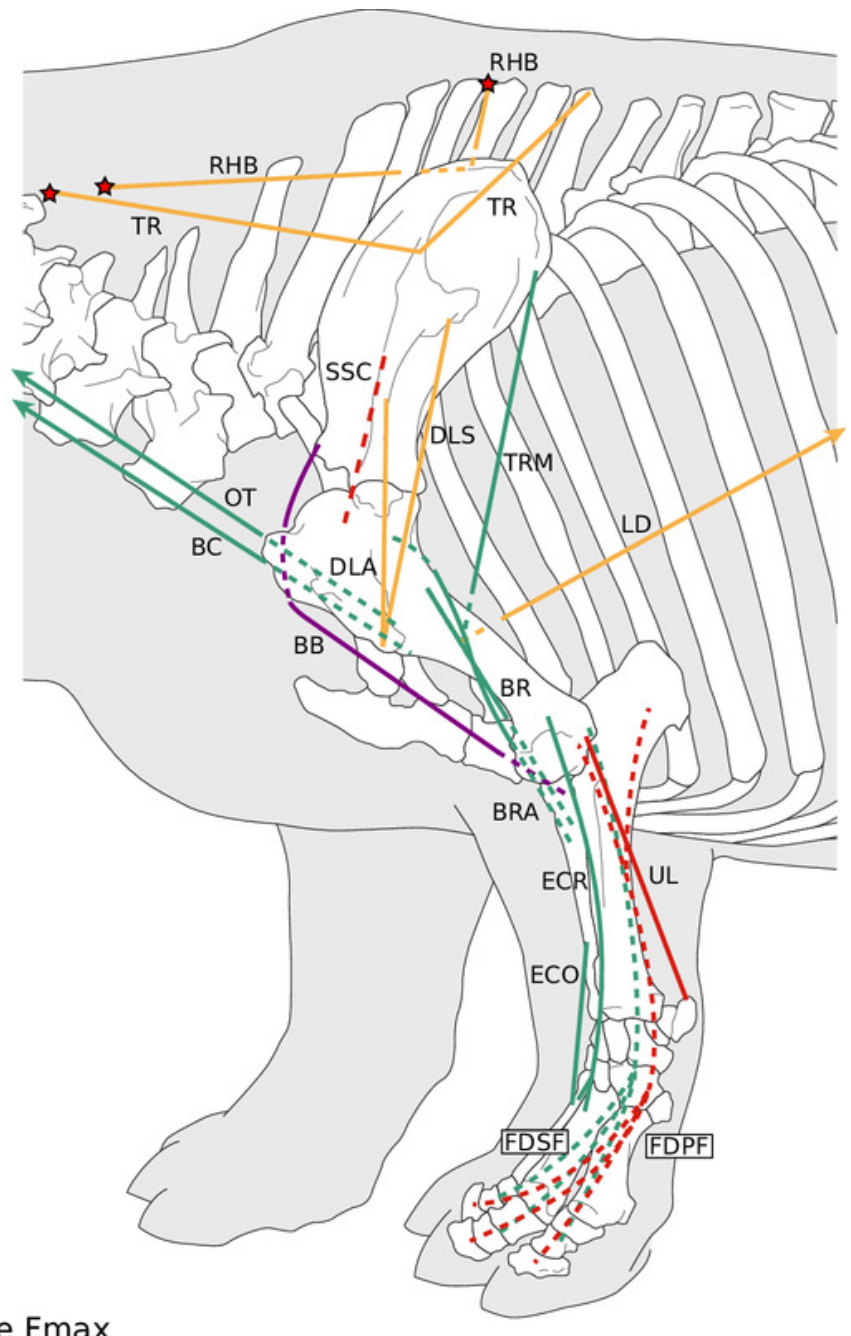

Relative Fmax

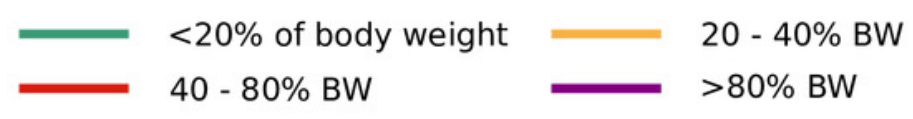

Insertion mainly on a fascia or ligament 
Figure 2

Photograph of the dissection of the superficial muscles of the left forelimb (lateral view) of the neonate individual of $C$. simum, with muscle labels.

Legend as in Fig. 1, except DL: deltoideus and TAcc: triceps brachii caput accessorius. 


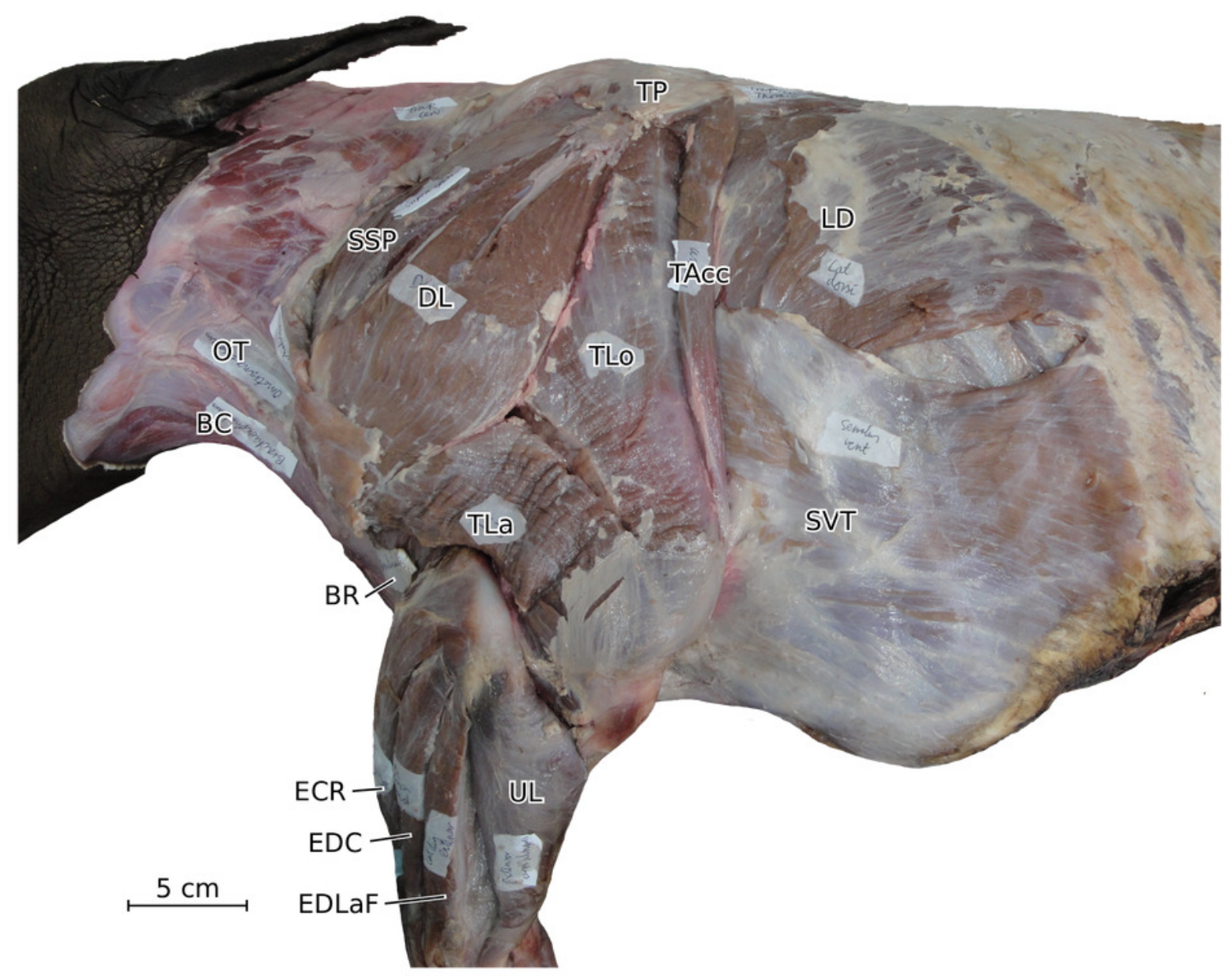


Figure 3

Muscular origins and insertions on the scapula of rhinoceroses.

(A) Lateral view. (B) Medial view. Muscle acronyms are in Table 2. This particular scapula comes from our adult $C$. simum, but the insertions are applicable to both species. 

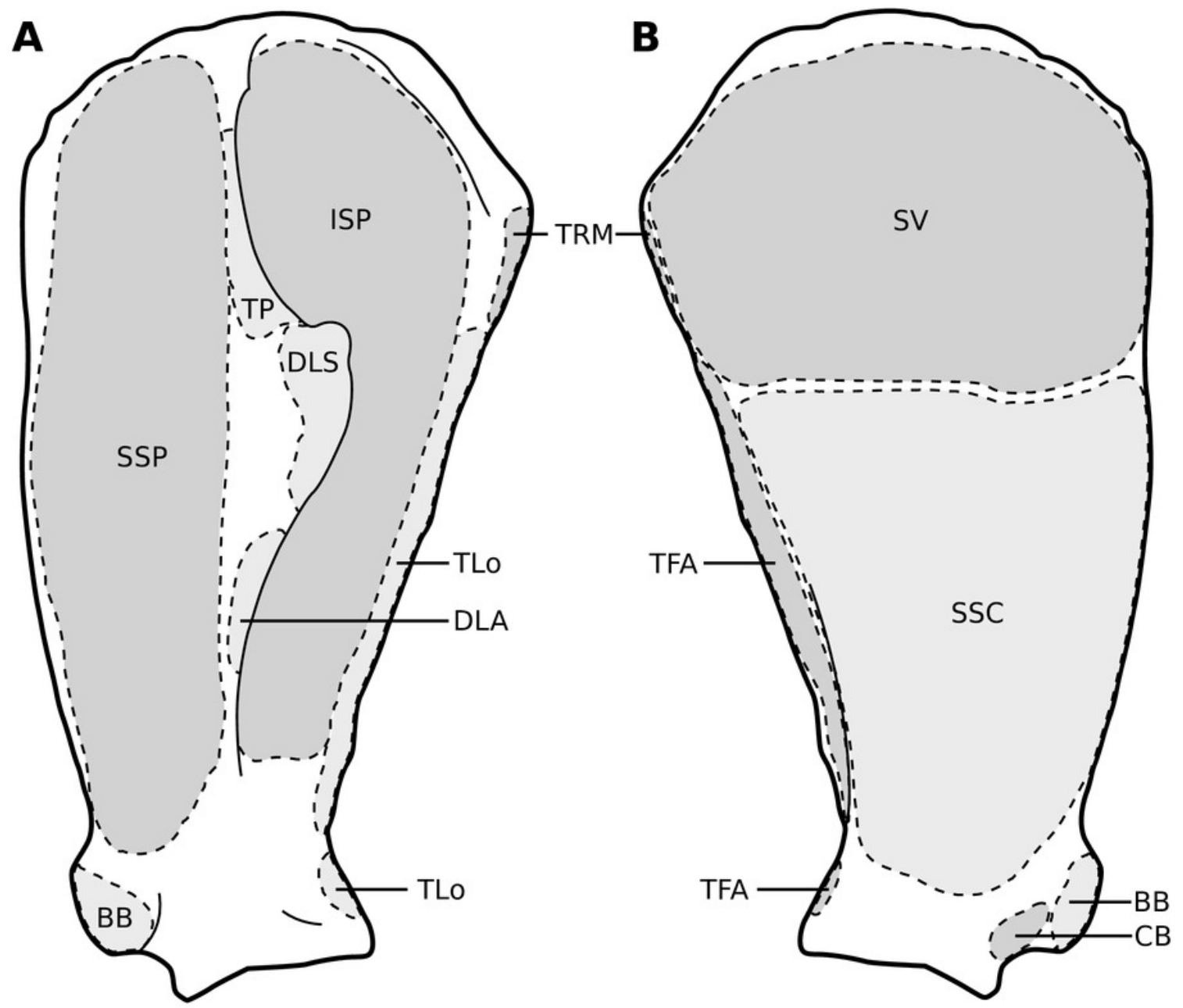
Figure 4

Muscular origins and insertions on the humerus of rhinoceroses.

(A) Cranial view. (B) Lateral view. (C) Caudal view. (D) Medial view. Muscle acronyms are in Table 2. This particular humerus comes from our adult $C$. simum, but the insertions are applicable to both species. 

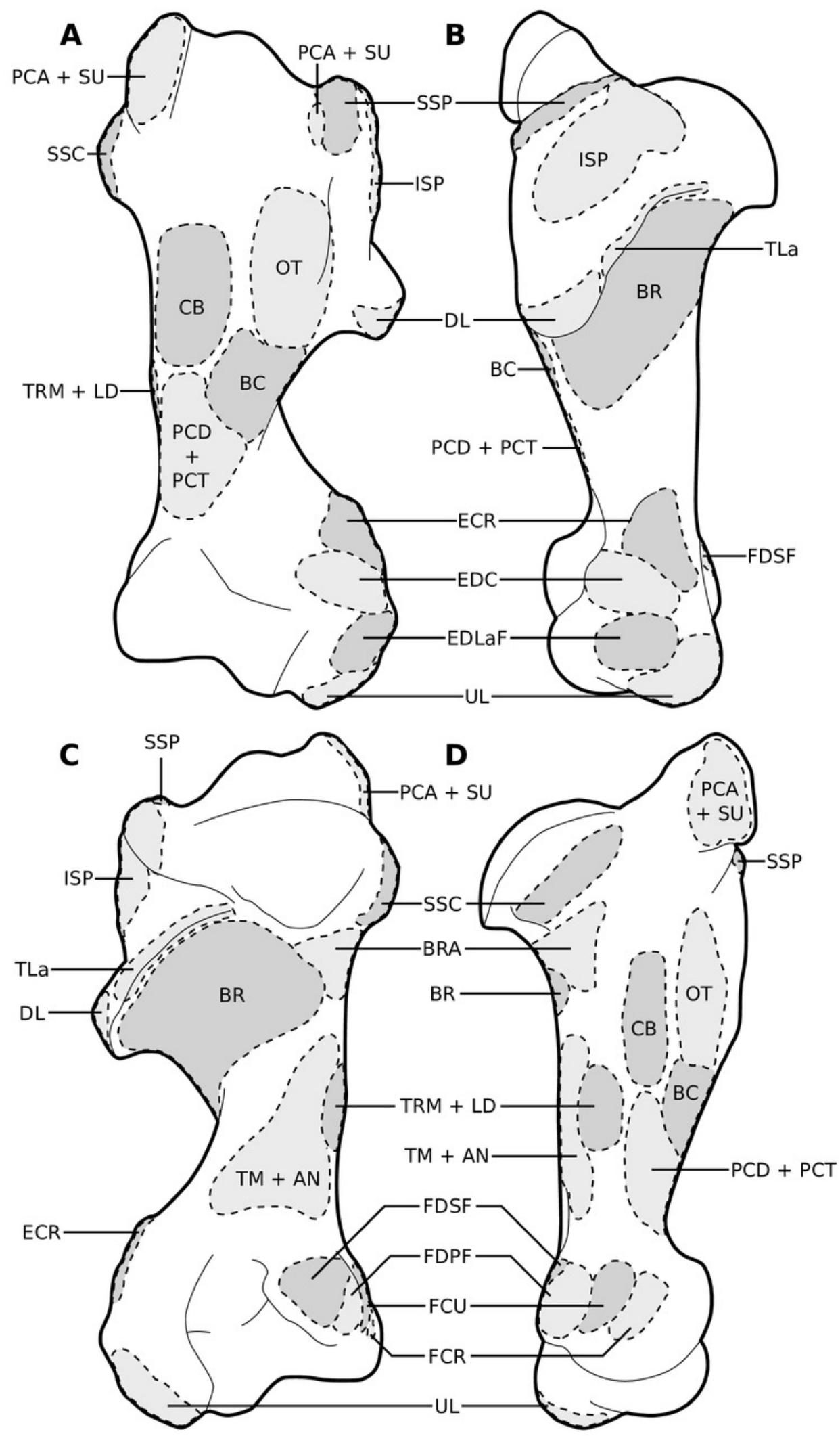


\section{Figure 5}

Muscular origins and insertions on the radius and ulna of rhinoceroses.

(A) Radius in cranial view. (B) Radius in caudal view. (C) Ulna in lateral view. (D) Ulna in medial view. The bones are shown to the same scale. The radial origin of the extensor digitorum communis was not evident in our $R$. unicornis specimens. Muscle acronyms are in Table 2; $\Pi$ : tendon of the triceps brachii. These bones come from our adult $C$. simum, but the insertions are applicable to both species. 


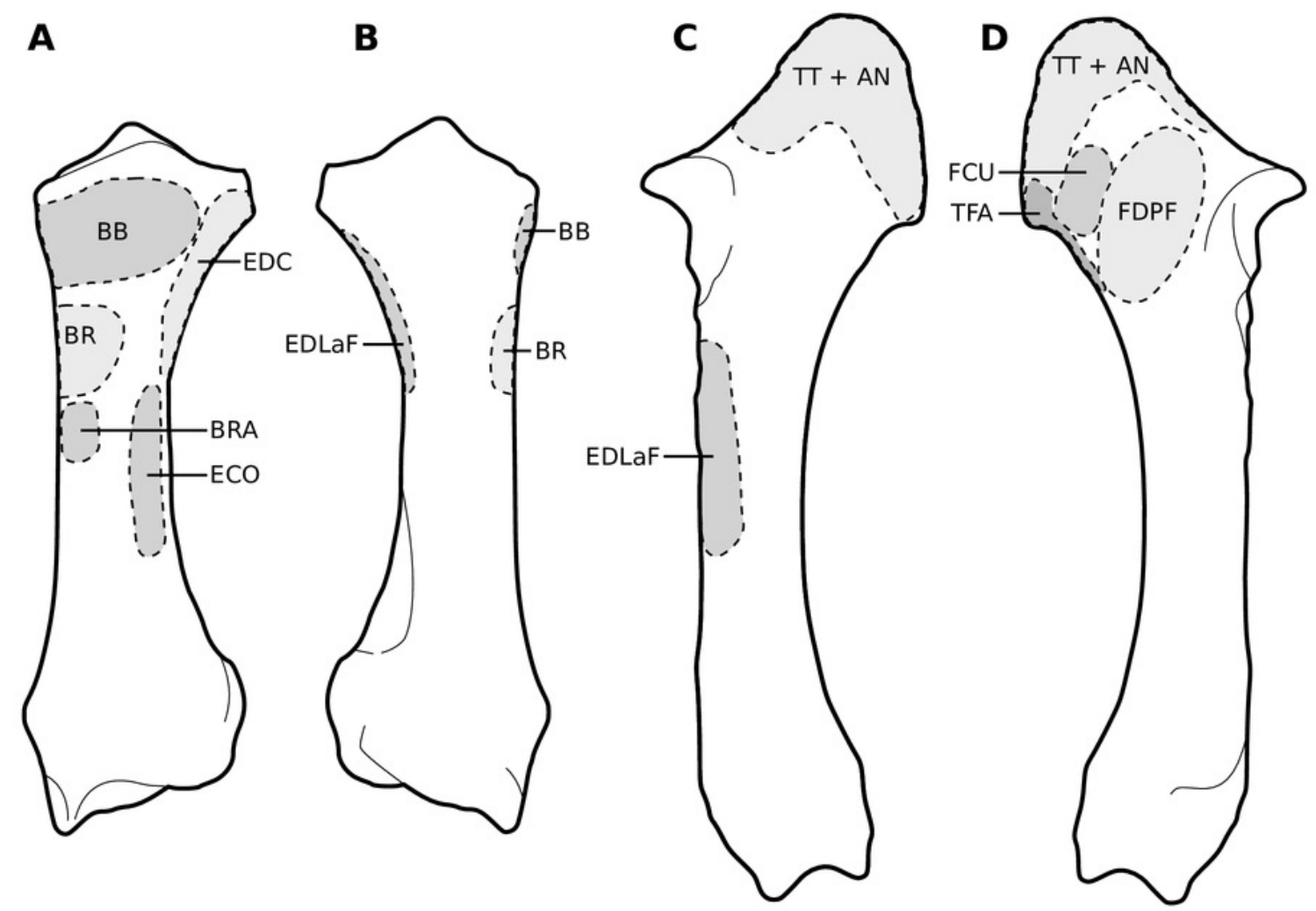




\section{Figure 6}

Diagram representing the muscles of the left hindlimb and their origins and insertions, lateral view.

Normalized Fmax values are those of our adult $R$. unicornis individual; muscles whose Fmax could not be determined (mm. psoas minor, fibularis tertius, fibularis longus) are classified as below $20 \%$ of body weight. The skeleton image is that of $R$. sondaicus (based on Pales \& Garcia, 1981), and is courtesy of https://www.archeozoo.org/archeozootheque/ and Michel Coutureau, under CC BY-NC-SA 4.0 license. The diagram is split in two to improve readability. Dashed lines represent muscles hidden by bones in lateral view. Please note that origins and insertions are not restricted to the exact points indicated by the lines.

(A) Psoas minor (PMN), psoas major (PMJ), iliacus (IL), obturator et gemelli (OG), tensor fasciae latae (TFL), gluteobiceps (GB), semimembranosus (SM), semitendinosus (ST), rectus femoris (RF), vastus medialis (VM) and lateralis (VL), quadriceps tendon (QT), patellar ligaments (PL), popliteus (PP), extensor digitorum longus (EDLo) and lateralis (EDLaH), common calcaneal tendon (CCT).

(B) Gluteus superficialis (GSP), medius (GMD) and profundus (GPF), sartorius (SRT), gracilis (GRC), pectineus (PTN), adductores (ADD), tibialis cranialis (TCR), fibularis tertius (FIT); fibularis longus (FIL), gastrocnemius (GC), common calcaneal tendon (CCT) and flexor digitorum superficialis (FDSH) and profundus (FDPH). 

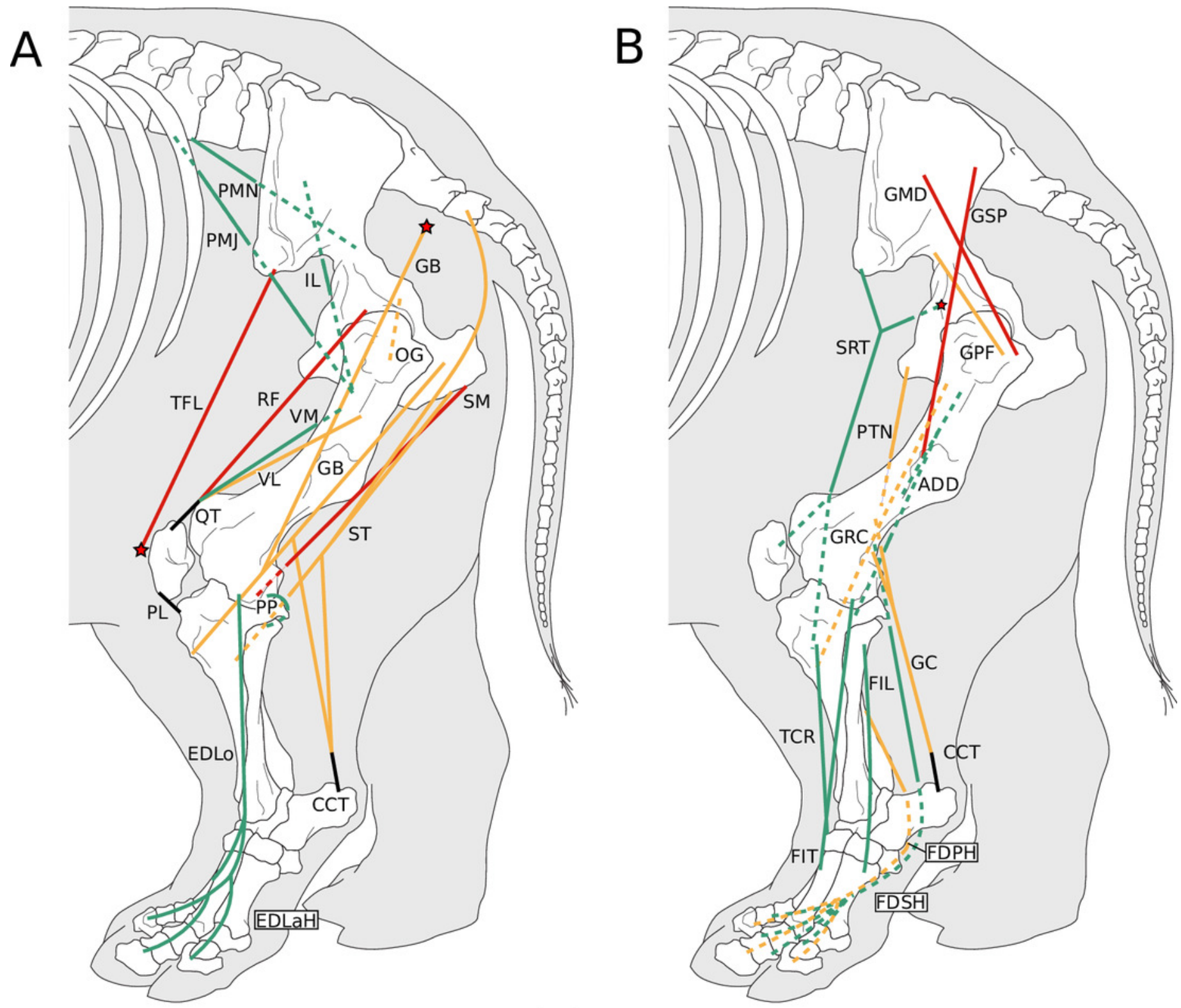

Relative Fmax

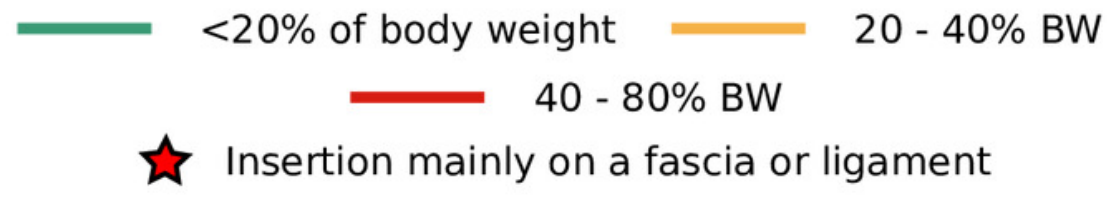




\section{Figure 7}

Photograph of the dissection of the superficial muscles of the left hindlimb (lateral view) of the neonate individual of $C$. simum, with muscle labels.

Legend as in Fig. 6. 


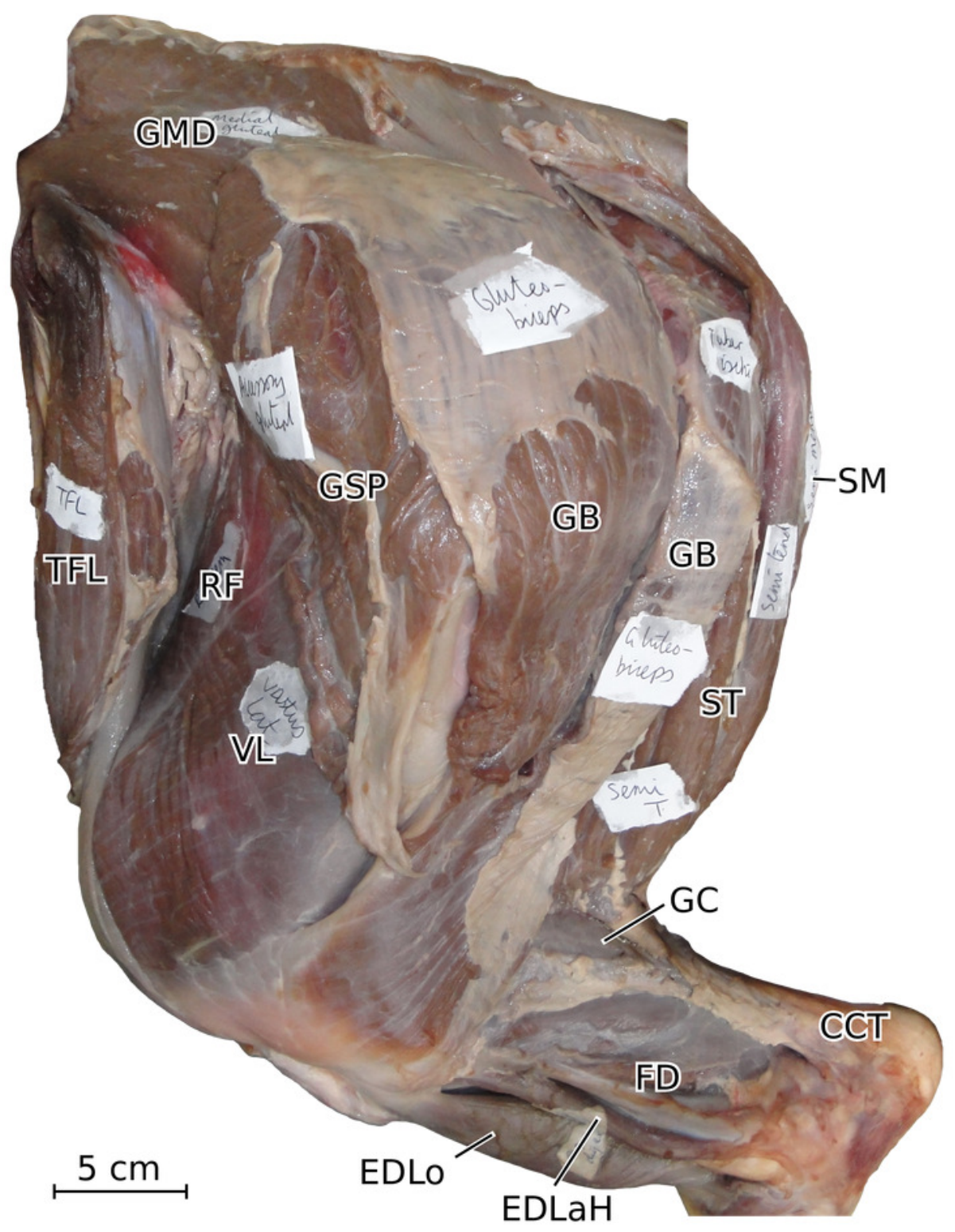


Figure 8

Muscular origins and insertions on the femur of rhinoceroses.

(A) Cranial view (B) Lateral view. (C) Caudal view. (D) Medial view. Muscle acronyms are in Table 3. This particular femur comes from our adult $C$. simum, but the insertions are applicable to both species.

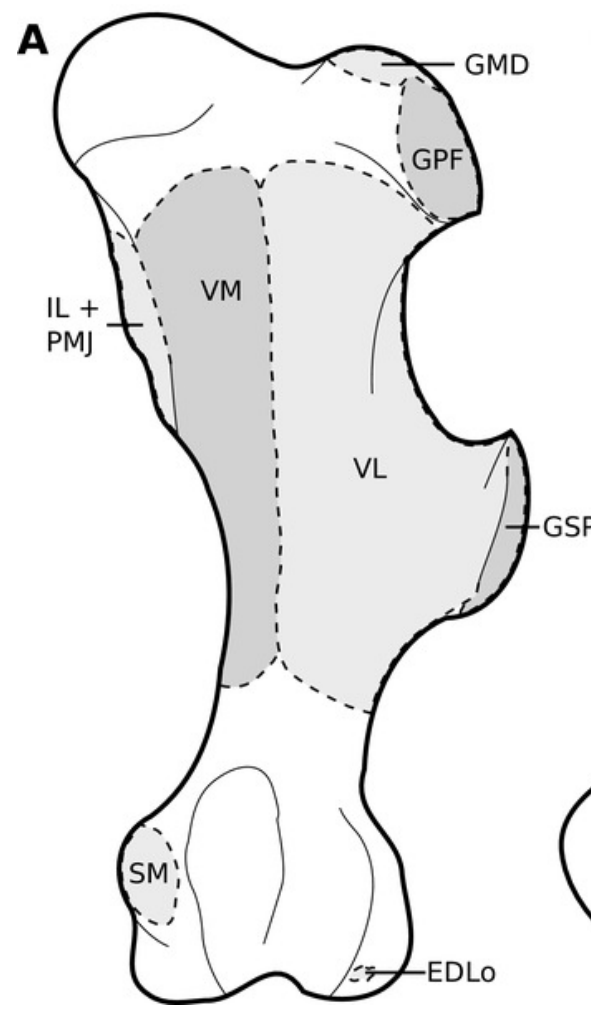

B
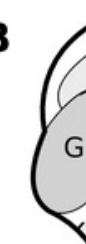

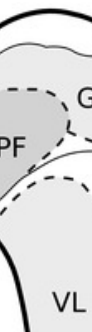

, GMD

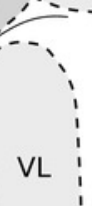

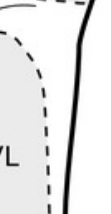

c

C
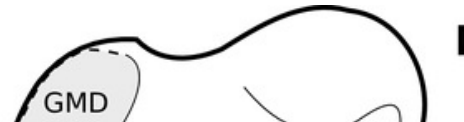

$j^{--}$

OG

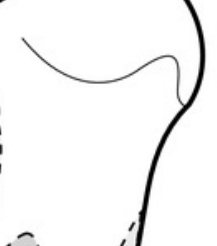

D

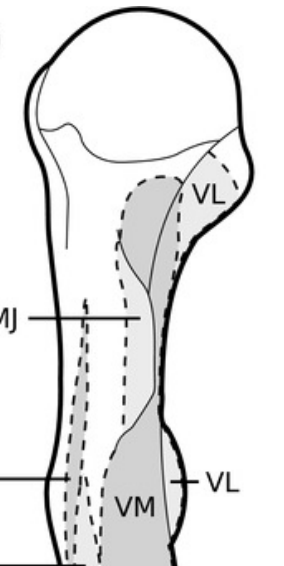


Figure 9

Muscular origins and insertions on the tibia and fibula of rhinoceroses.

(A) Cranial view. (B) Lateral view. (C) Caudal view. (D) Medial view. The patellar ligaments ( $\mathrm{PL}$, in pink) are shown given their important action in transmitting the force generated by the quadriceps femoris on the patella. Muscle acronyms are in Table 3. These bones come from our adult $C$. simum, but the insertions are applicable to both species.

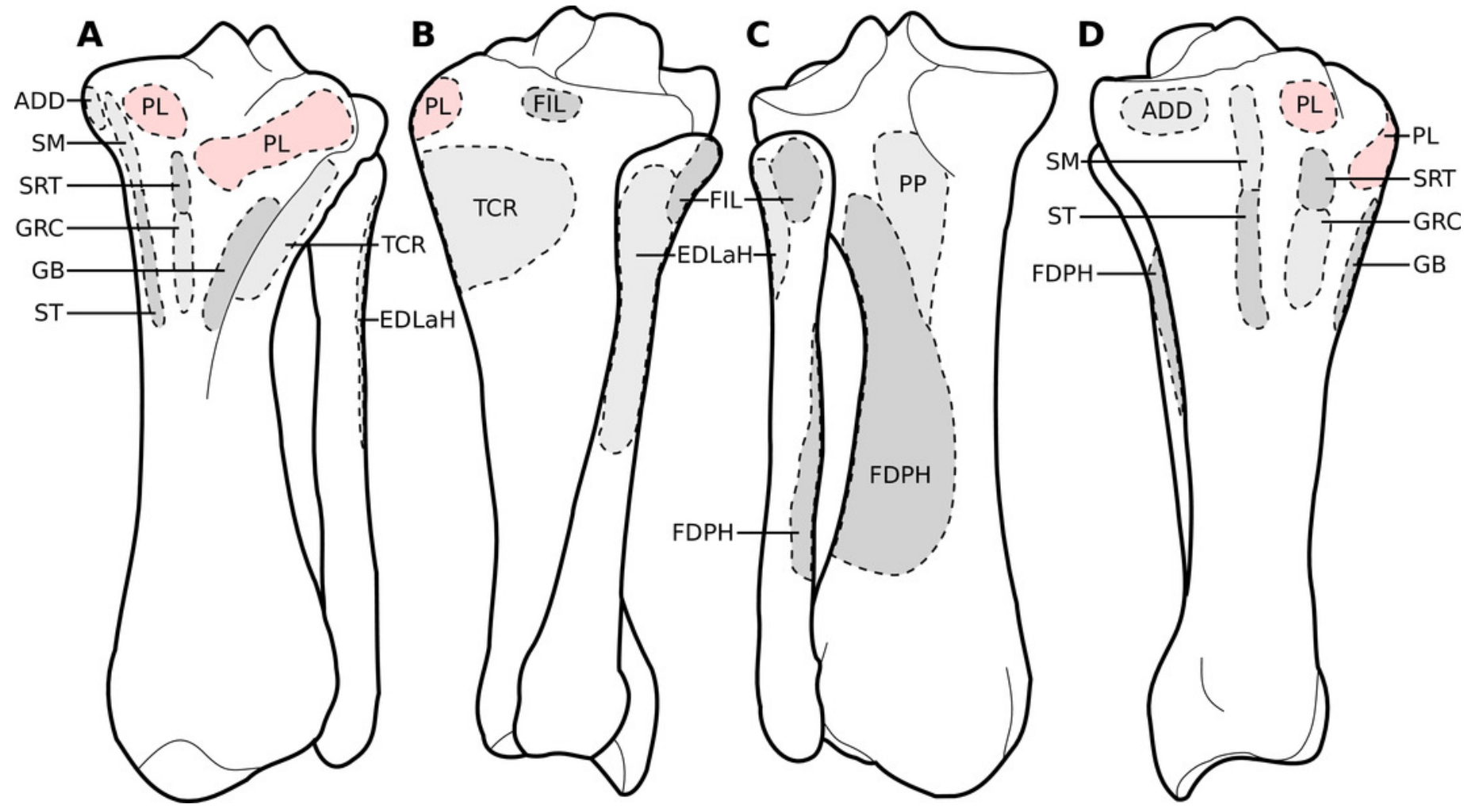


Figure 10

Normalized Fmax of the muscles of the forelimb of our four rhinoceroses.

Fmax was normalized by dividing it by the total weight of the animal, in Newtons (N). *:

Normalized Fmax calculated but close to 0\%. Muscle acronyms are in Table 2. Muscle categories follow Barone (2010).
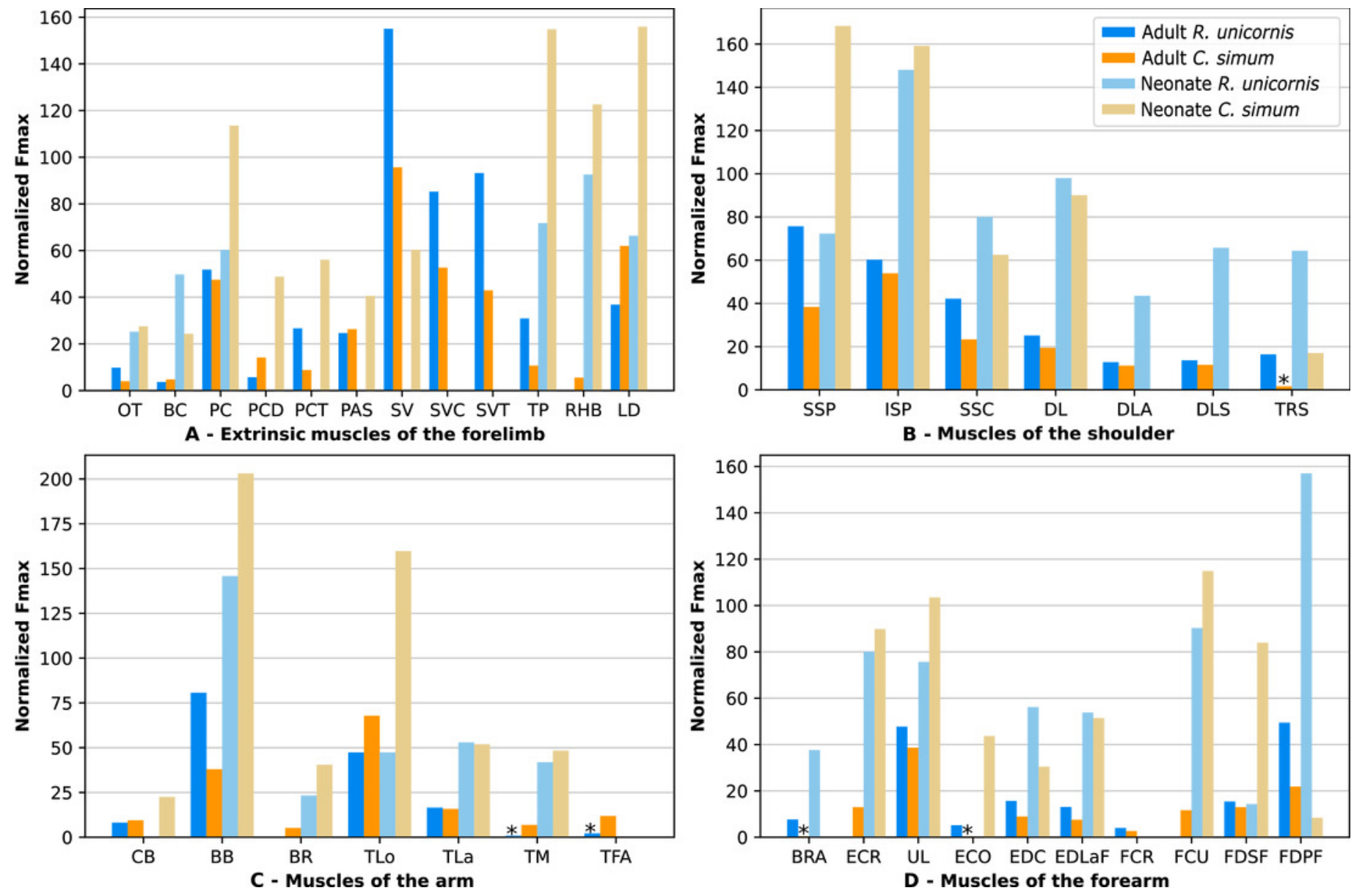


\section{Figure 11}

Normalized average fascicle length (\%) of the muscles of the forelimb, averaged from the four specimens for each muscle.

Error bars correspond to one standard deviation above and below the mean. Muscle acronyms are in Table 2.

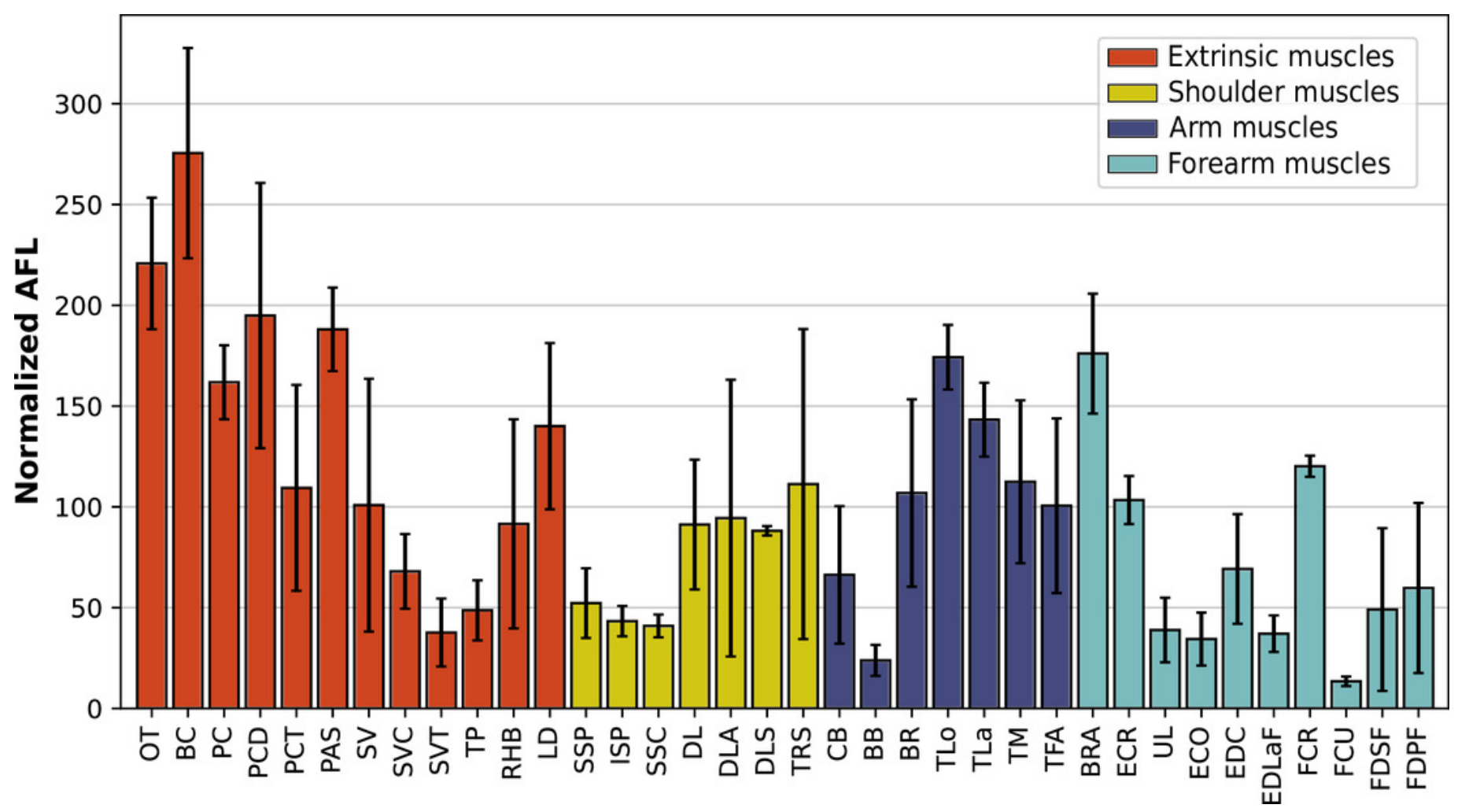


Figure 12

Normalized Fmax of the muscles of the hindlimb of our four rhinoceroses.

Fmax was normalized by dividing it by the total weight of the animal, in Newtons (N). *:

Normalized Fmax calculated but close to 0\%. FD: flexores digitorum, other muscle acronyms are in Table 3. Muscle categories follow Barone (2010), thigh muscles are divided for readability reasons. Value for the gluteobiceps (GB) in the adult R. unicornis is incomplete.
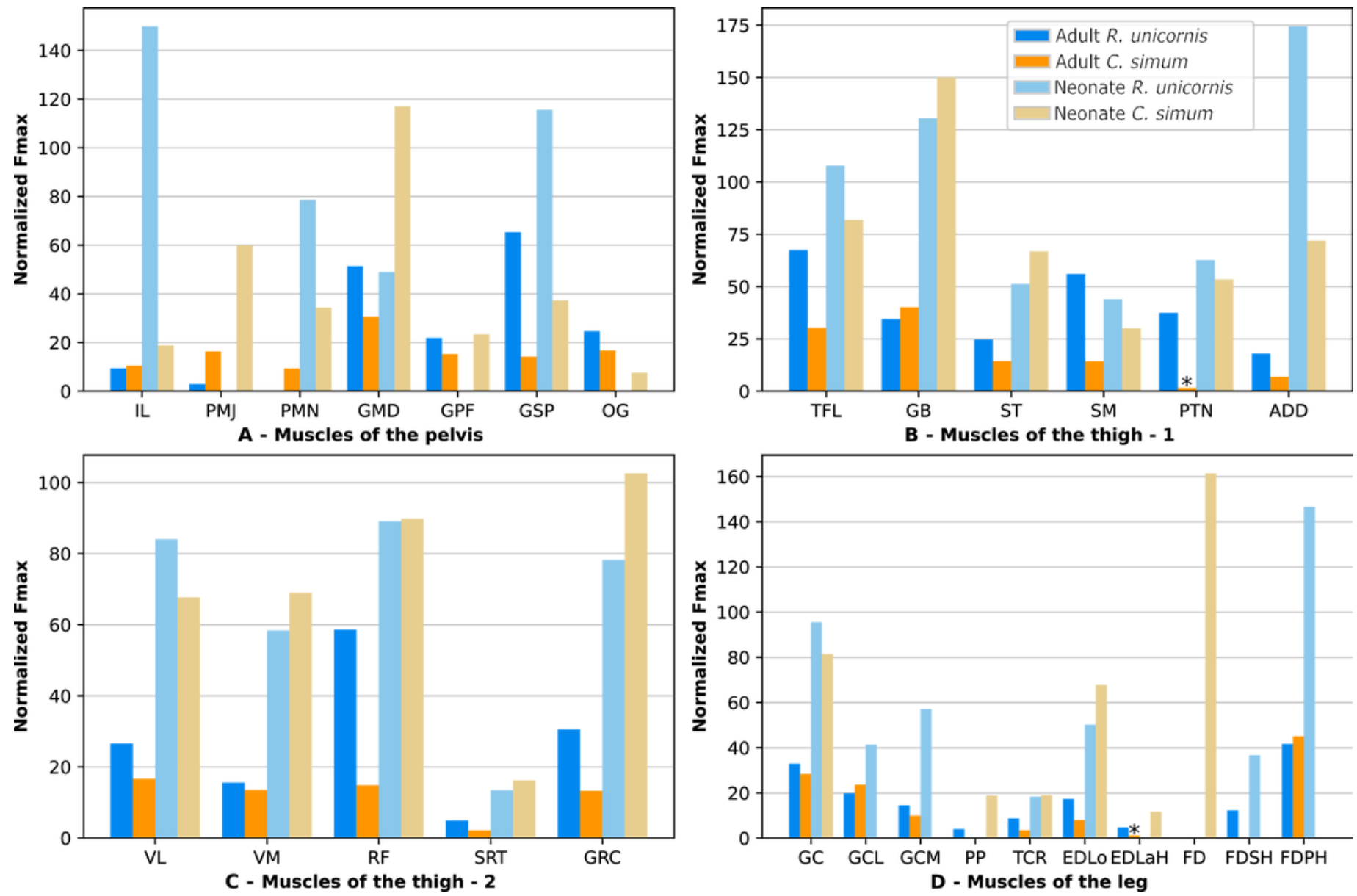


\section{Figure 13}

Normalized average fascicle length (\%) of the muscles of the hindlimb, averaged from the four specimens for each muscle.

Error bars correspond to one standard deviation above and below the average. FD: flexores digitorum, other muscle acronyms are in Table 3.

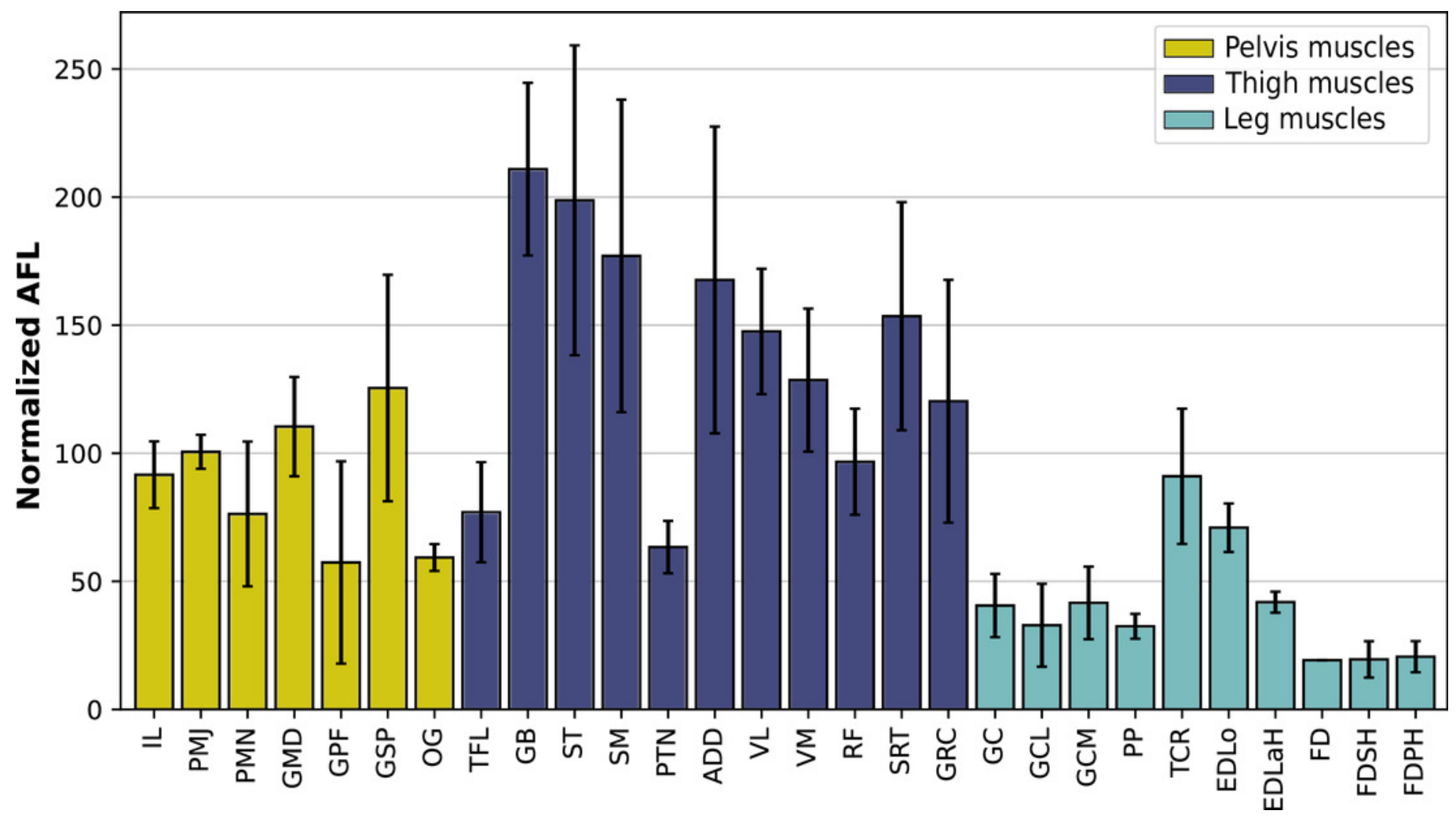


Figure 14

Ratios of normalized Fmax of the neonate divided by the normalized Fmax of the adult, for both species.

(A) Muscles of the forelimb. (B) Muscles of the hindlimb. The dashed line indicates approximate isometric scaling with body weight (i.e. ratio of 1). Muscles acronyms are in Tables 2 (forelimb) and 3 (hindlimb). 


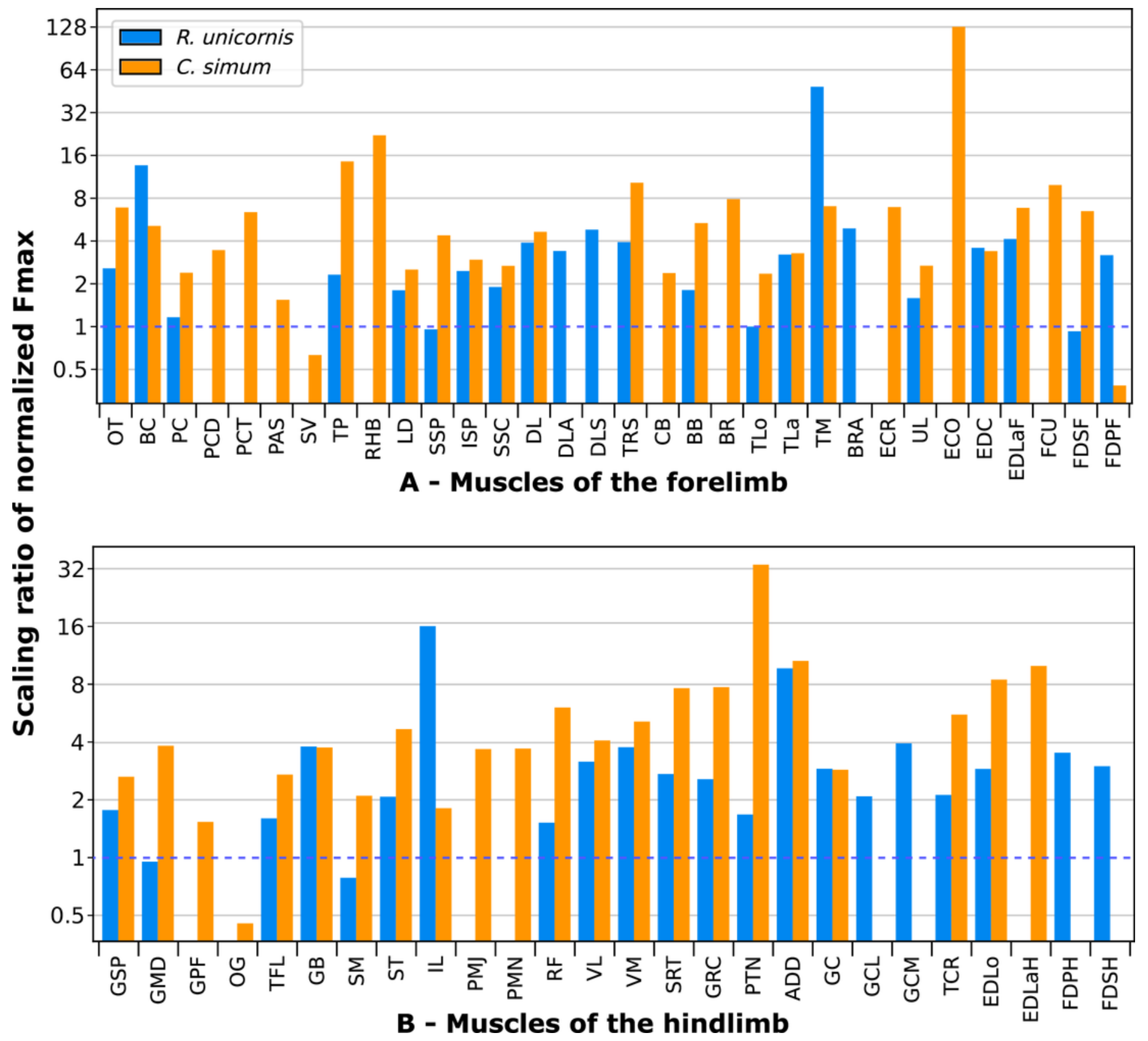




\section{Table 1 (on next page)}

Rhinoceros specimens studied.

The adult specimens were weighed at death. Both neonates were weighed after thawing and evisceration. 
1 Table 1. Rhinoceros specimens studied. The adult specimens were weighed at death. Both neonates were 2 weighed after thawing and evisceration.

\begin{tabular}{|c|c|c|c|c|c|}
\hline Species & Age & Body mass & Sex & Condition & Origin \\
\hline $\begin{array}{l}\text { Ceratotherium } \\
\text { simum }\end{array}$ & $>40 \mathrm{yr}$ & $2160 \mathrm{~kg}$ & $\mathrm{~F}$ & $\begin{array}{l}\text { Weight loss and } \\
\text { generalized weakness }\end{array}$ & $\begin{array}{l}\text { ZSL Whipsnade Zoo, } \\
\text { UK }\end{array}$ \\
\hline $\begin{array}{l}\text { Ceratotherium } \\
\text { simum }\end{array}$ & $0 \mathrm{yr}$ & $47 \mathrm{~kg}$ & $\mathrm{M}$ & Stillborn & $\begin{array}{l}\text { Details lost } \\
\text { (European zoo) }\end{array}$ \\
\hline $\begin{array}{l}\text { Rhinoceros } \\
\text { unicornis }\end{array}$ & $38 \mathrm{yr}$ & $2065 \mathrm{~kg}$ & $\mathrm{~F}$ & Ataxia & $\begin{array}{l}\text { Woburn Safari Park, } \\
\text { UK }\end{array}$ \\
\hline $\begin{array}{l}\text { Rhinoceros } \\
\text { unicornis }\end{array}$ & $0 \mathrm{yr}$ & $43 \mathrm{~kg}$ & unknown & Stillborn & $\begin{array}{l}\text { Munich Hellabrunn } \\
\text { Zoo, Germany }\end{array}$ \\
\hline
\end{tabular}




\section{Table 2 (on next page)}

General origins and insertions of the muscles of the forelimb in rhinoceroses, with their main action(s) (anatomically estimated function, based on Barone, 2010).

Abb.: abbreviation. 1: muscle found only in the neonate $R$. unicornis. 
1 Table 2. General origins and insertions of the muscles of the forelimb in rhinoceroses, with their 2 main action(s) (anatomically estimated function, based on Barone, 2010). Abb.: abbreviation. 1: 3 muscle found only in the neonate $R$. unicornis

\begin{tabular}{|c|c|c|c|c|}
\hline Name & Abb. & Origin & Insertion & Action \\
\hline $\begin{array}{r}M . \\
\text { omotransversarius }\end{array}$ & OT & $\begin{array}{l}\text { Wing of the atlas, and likely } \\
\text { transverse processes of the } \\
\text { first cervical vertebrae }\end{array}$ & $\begin{array}{l}\text { Unclear, most likely distal part } \\
\text { of scapular spine and } \\
\text { craniomedial humerus } \\
\text { proximal to brachiocephalicus }\end{array}$ & Forelimb protraction \\
\hline $\begin{array}{r}M . \\
\text { brachiocephalicus }\end{array}$ & $\mathrm{BC}$ & $\begin{array}{l}\text { Mastoid process of temporal } \\
\text { bone }\end{array}$ & $\begin{array}{l}\text { Proximo-cranial aspect of the } \\
\text { humeral crest }\end{array}$ & $\begin{array}{l}\text { Neck flexion and } \\
\text { rotation, forelimb } \\
\text { protraction }\end{array}$ \\
\hline $\begin{array}{r}\text { M. pectoralis } \\
\text { descendens }\end{array}$ & PCD & $\begin{array}{l}\text { Manubrium, sternum and } \\
\text { costal cartilages }\end{array}$ & $\begin{array}{l}\text { Antebrachial fascia and crest } \\
\text { of humerus }\end{array}$ & Shoulder adduction \\
\hline $\begin{array}{r}\text { M. pectoralis } \\
\text { transversus }\end{array}$ & PCT & $\begin{array}{l}\text { Manubrium, sternum and } \\
\text { costal cartilages }\end{array}$ & $\begin{array}{l}\text { Antebrachial fascia and crest } \\
\text { of humerus }\end{array}$ & Shoulder adduction \\
\hline $\begin{array}{r}\text { M. pectoralis } \\
\text { ascendens }\end{array}$ & PCA & Sternum and costal cartilages & $\begin{array}{l}\text { Humerus, medial lesser } \\
\text { tubercle and cranial greater } \\
\text { tubercle with subclavius }\end{array}$ & $\begin{array}{l}\text { Thorax support, } \\
\text { forelimb retraction. }\end{array}$ \\
\hline M. subclavius & SU & Sternum and costal cartilages & $\begin{array}{l}\text { Proximal humerus with } \\
\text { pectoralis ascendens, and } \\
\text { likely dorsal scapula via } \\
\text { fasciae }\end{array}$ & $\begin{array}{l}\text { Thorax support, } \\
\text { forelimb retraction. }\end{array}$ \\
\hline $\begin{array}{r}\text { Mm. serrati } \\
\text { ventrales }\end{array}$ & SV & $\begin{array}{l}\text { See } m \text {. serratus ventralis } \\
\text { thoracis and } m \text {. serratus } \\
\text { ventralis cervicis }\end{array}$ & $\begin{array}{l}\text { Medial aspect of the scapula, } \\
\text { proximal half }\end{array}$ & $\begin{array}{l}\text { See } m \text {. serratus } \\
\text { ventralis thoracis and } \\
m . \text { serratus ventralis } \\
\text { cervicis }\end{array}$ \\
\hline $\begin{array}{r}\text { M. serratus } \\
\text { ventralis thoracis }\end{array}$ & SVT & Distal aspect of the first ribs & $\begin{array}{l}\text { Medial aspect of the scapula, } \\
\text { proximal half }\end{array}$ & $\begin{array}{l}\text { Supports the thorax } \\
\text { between the forelimbs }\end{array}$ \\
\hline $\begin{array}{r}\text { M. serratus } \\
\text { ventralis cervicis }\end{array}$ & SVC & $\begin{array}{l}\text { Transverse processes of } \\
\text { cervical vertebrae }\end{array}$ & $\begin{array}{l}\text { Medial aspect of the scapula, } \\
\text { proximal half }\end{array}$ & $\begin{array}{l}\text { Supports the head and } \\
\text { neck between the } \\
\text { forelimbs }\end{array}$ \\
\hline M. trapezius & $\mathrm{TP}$ & $\begin{array}{l}\text { Nuchal ligament, thoracic } \\
\text { vertebrae } 1 \text { to } 12 \text {, dorsal } \\
\text { aspect of the ribs }\end{array}$ & $\begin{array}{l}\text { Caudo-proximal part of the } \\
\text { scapular spine }\end{array}$ & Forelimb abduction \\
\hline Mm. rhomboidei & RHB & $\begin{array}{l}\text { Nuchal and dorsoscapular } \\
\text { ligaments }\end{array}$ & $\begin{array}{l}\text { Scapular cartilage, medial } \\
\text { aspect }\end{array}$ & $\begin{array}{l}\text { Forelimb abduction, } \\
\text { neck extension }\end{array}$ \\
\hline M. latissimus dorsi & LD & $\begin{array}{l}\text { Thoracolumbar fascia, and } \\
\text { overall large portion of the } \\
\text { dorsal rib cage }\end{array}$ & $\begin{array}{l}\text { Teres major tuberosity, } \\
\text { merging with teres major }\end{array}$ & $\begin{array}{l}\text { Shoulder } \\
\text { extensionForelimb } \\
\text { retraction }\end{array}$ \\
\hline M. supraspinatus & SSP & Supraspinous fossa & $\begin{array}{l}\text { Summit of the greater tubercle, } \\
\text { above the infraspinatus } \\
\text { insertion }\end{array}$ & Shoulder extension \\
\hline M. infraspinatus & ISP & $\begin{array}{l}\text { Infraspinous fossa and dorsal } \\
\text { tip of the scapular tuberosity }\end{array}$ & $\begin{array}{l}\text { Greater tubercle, caudodistal to } \\
\text { supraspinatus insertion }\end{array}$ & $\begin{array}{l}\text { Shoulder abduction, } \\
\text { stabilization and } \\
\text { extension }\end{array}$ \\
\hline M. subscapularis & SSC & $\begin{array}{l}\text { Medial aspect of the scapula, } \\
\text { distal half }\end{array}$ & $\begin{array}{l}\text { Lesser tubercle, likely the } \\
\text { convexity, and articular } \\
\text { capsule of the shoulder }\end{array}$ & Shoulder adduction \\
\hline M. deltoideus & $\begin{array}{l}\text { DL } \\
\text { DLS } \\
\text { DLA }\end{array}$ & $\begin{array}{l}\text { Pars scapularis: Tuberosity } \\
\text { of the scapular spine + fascia } \\
\text { over infraspinatus } \\
\text { Pars acromialis: distal end } \\
\text { of scapular spine }\end{array}$ & $\begin{array}{l}\text { Deltoid tuberosity of the } \\
\text { humerus }\end{array}$ & $\begin{array}{l}\text { Shoulder abduction, } \\
\text { and shoulder flexion } \\
\text { when combined with } \\
\text { teres major }\end{array}$ \\
\hline
\end{tabular}




\begin{tabular}{|c|c|c|c|c|}
\hline M. teres major & TRM & $\begin{array}{l}\text { Medial aspect of the scapula, } \\
\text { proximo-caudal border }\end{array}$ & $\begin{array}{l}\text { Teres major tuberosity, } \\
\text { merging with the latissimus } \\
\text { dorsi }\end{array}$ & $\begin{array}{l}\text { Shoulder adduction } \\
\text { and internal rotation, } \\
\text { and shoulder flexion } \\
\text { when combined with } \\
\text { deltoideus }\end{array}$ \\
\hline $\begin{array}{r}M . \\
\text { coracobrachialis }\end{array}$ & $\mathrm{CB}$ & $\begin{array}{l}\text { Coracoid process of the } \\
\text { scapula: medial aspect, } \\
\text { cranio-distal angle }\end{array}$ & $\begin{array}{l}\text { Cranio-medial humerus, close } \\
\text { to brachiocephalicus and } \\
\text { omotranversarius }\end{array}$ & $\begin{array}{l}\text { Shoulder adduction } \\
\text { and internal rotation }\end{array}$ \\
\hline M. biceps brachï & BB & $\begin{array}{l}\text { Supraglenoid tubercle of the } \\
\text { scapula }\end{array}$ & $\begin{array}{l}\text { Medial aspect of the proximal } \\
\text { epiphysis of the radius (radial } \\
\text { tuberosity) }\end{array}$ & $\begin{array}{l}\text { Elbow and shoulder } \\
\text { flexion }\end{array}$ \\
\hline M. brachialis & $\mathrm{BR}$ & $\begin{array}{l}\text { Humeral neck, extending } \\
\text { cranio-distally }\end{array}$ & Distal to that of biceps brachii & Elbow flexion \\
\hline $\begin{array}{l}\text { M. triceps brachii } \\
\text { caput longum }\end{array}$ & TLo & $\begin{array}{l}\text { Elongated origin on the } \\
\text { whole caudal border of the } \\
\text { scapula }\end{array}$ & $\begin{array}{l}\text { Olecranon, with a common } \\
\text { tendon for the whole triceps }\end{array}$ & $\begin{array}{l}\text { Elbow and shoulder } \\
\text { extension }\end{array}$ \\
\hline $\begin{array}{r}\text { M. triceps brachii } \\
\text { caput laterale }\end{array}$ & TLa & Tricipital line of the humerus & $\begin{array}{l}\text { Olecranon, with a common } \\
\text { tendon for the whole triceps }\end{array}$ & Elbow extension \\
\hline $\begin{array}{l}\text { M. triceps brachii } \\
\text { caput mediale }\end{array}$ & $\mathrm{TM}$ & $\begin{array}{l}\text { Caudo-medial part of the } \\
\text { humeral diaphysis, caudal to } \\
\text { the tuberosity of teres major. }\end{array}$ & $\begin{array}{l}\text { Olecranon, with a common } \\
\text { tendon for the whole triceps }\end{array}$ & Elbow extension \\
\hline M. anconeus ${ }^{1}$ & AN & $\begin{array}{l}\text { Distal medial humeral shaft, } \\
\text { just above the olecranon } \\
\text { fossa }\end{array}$ & Lateral side of the olecranon & $\begin{array}{l}\text { Elbow extension; } \\
\text { accessory to the } \\
\text { triceps }\end{array}$ \\
\hline $\begin{array}{r}\text { M. tensor fasciae } \\
\text { antebrachii }\end{array}$ & TFA & $\begin{array}{l}\text { Elongated origin on the } \\
\text { caudal border of the scapula }\end{array}$ & $\begin{array}{l}\text { Antebrachial fasciae and } \\
\text { caudal surface of the olecranon }\end{array}$ & Elbow extension \\
\hline M. brachioradialis & BRA & $\begin{array}{l}\text { Proximomedial humerus, } \\
\text { below the neck }\end{array}$ & $\begin{array}{l}\text { Craniomedial radius, distal to } \\
\text { that of the brachialis }\end{array}$ & Forearm supination \\
\hline $\begin{array}{r}\text { M. extensor carpi } \\
\text { radialis }\end{array}$ & ECR & Humerus, epicondylar crest & $\begin{array}{l}\text { Dorsal aspect of proximal } \\
\text { MCIII + small tendon on MCII }\end{array}$ & Wrist extension \\
\hline M. ulnaris lateralis & UL & $\begin{array}{l}\text { Summit of the lateral } \\
\text { epicondyle of the humerus }\end{array}$ & $\begin{array}{l}\text { Pisiform bone, and maybe base } \\
\text { of the plantar aspect of the } \\
\text { MCIV }\end{array}$ & Wrist flexion \\
\hline $\begin{array}{r}\text { M. extensor carpi } \\
\text { obliquus }\end{array}$ & $\mathrm{ECO}$ & $\begin{array}{l}\text { Craniolateral surface of } \\
\text { radius }\end{array}$ & Proximal part of dorsal MCII & Weak wrist extension \\
\hline $\begin{array}{r}\text { M. extensor } \\
\text { digitorum } \\
\text { communis }\end{array}$ & EDC & $\begin{array}{l}\text { Above the radial fossa of the } \\
\text { humerus, and lateral aspect } \\
\text { of the radial head (C. simum } \\
\text { only) }\end{array}$ & $\begin{array}{l}\text { Dorsal surface of each distal } \\
\text { phalanx }\end{array}$ & $\begin{array}{l}\text { Metacarpo/interphalan } \\
\text { geal joints extension }\end{array}$ \\
\hline $\begin{array}{r}\text { M. extensor } \\
\text { digitorum lateralis }\end{array}$ & EDLaF & $\begin{array}{l}\text { Lateral condyle of the } \\
\text { humerus, craniolateral } \\
\text { aspect, and proximo-lateral } \\
\text { radius and ulna }\end{array}$ & $\begin{array}{l}\text { Dorsal aspect of the proximal } \\
\text { phalanx of digit IV }\end{array}$ & $\begin{array}{l}\text { Digit IV joints } \\
\text { extension }\end{array}$ \\
\hline $\begin{array}{r}\text { M. flexor carpi } \\
\text { radialis }\end{array}$ & FCR & $\begin{array}{l}\text { Medial epicondyle of the } \\
\text { humerus, medial aspect, } \\
\text { cranial to that of } F C U\end{array}$ & $\begin{array}{l}\text { Proximo-plantar part of MCII } \\
\text { and MCIII }\end{array}$ & Wrist flexion \\
\hline $\begin{array}{r}\text { M. flexor carpi } \\
\text { ulnaris }\end{array}$ & $\mathrm{FCU}$ & $\begin{array}{l}\text { Ulnar head: Olecranon, } \\
\text { medial to the triceps } \\
\text { Humeral head: medial } \\
\text { epicondyle, between the } \\
\text { origins of } F D P \text { and } F C R\end{array}$ & Pisiform bone, palmar aspect & Wrist flexion \\
\hline $\begin{array}{r}\text { M. flexor } \\
\text { digitorum } \\
\text { superficialis }\end{array}$ & FDSF & $\begin{array}{l}\text { Medial epicondyle of the } \\
\text { humerus, caudo-medial } \\
\text { aspect; most caudal origin of } \\
\text { the four flexors }\end{array}$ & $\begin{array}{l}\text { Second phalanx of all three } \\
\text { digits, plantar aspect }\end{array}$ & $\begin{array}{l}\text { Metacarpo/interphalan } \\
\text { geal joints flexion }\end{array}$ \\
\hline
\end{tabular}




\begin{tabular}{|c|c|c|c|c|}
\hline $\begin{array}{c}\text { M. flexor } \\
\text { digitorum } \\
\text { profundus }\end{array}$ & FDPF & $\begin{array}{l}\text { Humeral head: medial } \\
\text { epicondyle of the humerus, } \\
\text { medial aspect, between } F D S \\
\text { and } F C U \\
\text { Ulnar head: medial } \\
\text { olecranon }\end{array}$ & $\begin{array}{l}\text { Distal phalanx of all three } \\
\text { digits, plantar aspect }\end{array}$ & $\begin{array}{l}\text { Metacarpo/interphalan } \\
\text { geal joints flexion }\end{array}$ \\
\hline
\end{tabular}




\section{Table 3(on next page)}

General origins and insertions of the muscles of the hindlimb in rhinoceroses, with their main action (anatomically estimated function, based on Barone, 2010).

Abb.: abbreviation. 
1 Table 3. General origins and insertions of the muscles of the hindlimb in rhinoceroses, with their

2 main action (anatomically estimated function, based on Barone, 2010).

3 Abb.: abbreviation.

Name

M. iliacus

M. psoas major

M. psoas minor

M. gluteus medius

M. gluteus profundus

M. gluteus superficialis

Mm. obturator et gemelli

M. tensor fasciae latae

M. gluteobiceps

quadriceps femoris

M. rectus femoris

M. vastus medialis

M. vastus lateralis

M. sartorius

M.

semimembranosus

M. semitendinosus

M. rectus femoris

VL

Abb. Origin

\begin{tabular}{|l|l|}
\hline IL & $\begin{array}{l}\text { Craniomedial surface of } \\
\text { illium. Iliac fossa }\end{array}$ \\
\hline PMJ & $\begin{array}{l}\text { Last ribs and thoracolumbar } \\
\text { vertebrae, ventral surfaces }\end{array}$
\end{tabular}

PMN Thoracolumbar vertebrae, ventral surfaces, medial to psoas major

GMD Wide origin along the dorsal caudal ilium

GPF Ventrocaudal part of the iliac wing

GSP Caudal corner of the ilium, caudal to gluteus medius

OG Ventral pubis and ischium

TFL Cranio-lateral tuber coxae, caudal to sartorius, cranial to gluteus medius

GB Biceps femoris: Ischial tuberosity

Gluteofemoralis: sacrosciatic ligament, dorsal ilium and sacral vertebral bodies

SM Ischial tuberosity, medial to semitendinosus

ST

One head on the sacrum and the first caudal vertebrae, one head on the ischial tuberosity, lateral to semimembranosus

QF $\quad$ See rectus femoris, vastus medialis and vastus lateralis

\section{RF}

Ilium, cranial to the acetabulum

VM Medial proximal femoral shaft

VL Lateral proximal femoral shaft, and a small attachment to the ventral ilium caudal to the iliac crest.

SRT One head on the inguinal ligament, the other on the tuber coxae ( $R$. unicornis only)
Insertion

Lesser trochanter, common with psoas major

Lesser trochanter, common

with iliacus

Psoas minor tubercle; most

fibres are continuous with the sartorius

Summit of the greater

trochanter, craniolateral side

Convexity (cranial part) of the greater trochanter, medial side

Third trochanter, lateral aspect

Trochanteric fossa

Fasciae latae, around the knee

Tibial crest and lateral patella as a fibrous band, and the calcaneus by a caudal extension

Medial epicondyle of femur, medial patella and medial proximal tibia of tibia

Patella, medial tibia, and leg fasciae down to the calcaneus

\section{Action}

Hip flexion, hip external rotation

Hip flexion, hip external rotation, lumbar region flexion Lumbar region flexion

Hip extension

Hip abduction, hip extension

Hip abduction

Hip external rotation, also hip abduction or adduction depending on the muscle Hip flexion, knee extension

Hip, knee and ankle extension (weakly).

Hip extension, knee flexion

Hip extension, knee flexion, ankle extension
One head on the proximomedial tibia, the other on the medial patella (R. unicornis only) 


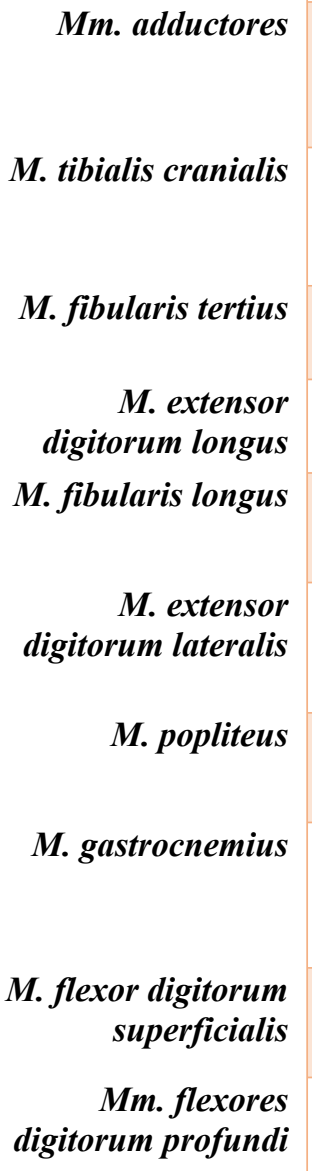

Mm. adductores

M. tibialis cranialis

M. fibularis tertius

M. extensor

.
EDI

FIL Head and shaft of the fibula and the lateral tibial cotyle

EDLa Lateral aspect of the fibular

$\mathrm{H}$ head

PP Lateral aspect of the lateral condyle of the femur, in a small fossa

GC Resp. lateral and medial

GCL supracondylar tuberosity for

GCM caput laterale and caput mediale

FDSH Supracondylar fossa

FDPH Caudal tibia and fibula
Fascia of the medial stifle and cranio-medial tibia

Distal third of the medial femur

Adductor brevis: medial femur; Adductor magnus: medial tibial condyle and fasciae around the knee Medial aspect of the medial cuneiform

Dorsal aspect of MT III

Dorsal aspect of each of the distal phalanges + MTII

Lateral malleolus and proximal lateral MTIV

Dorsolateral aspect of the distal phalanx of digit IV

Proximal caudal tibia

Cranial tuber calcanei

Plantar aspect of the proximal part of the second phalanges of all digits

Plantar aspect of the distal phalanx of each digit
Hip adduction, tensor of the fasciae latae Hip adduction, flexion and internal rotation

Hip adduction

Ankle flexion

Auxiliary to the tibialis cranialis

Digit extension, ankle flexion

Abduction and external rotation of the ankle

Extension and weak abduction of digit IV

Knee flexion and internal rotation.

Ankle extension

Metacarpo/interphalan geal joints flexion

Metacarpo/interphalan geal joints flexion 


\section{Table 4 (on next page)}

Comparison of the PCSA (in $\mathrm{cm}^{2}$ ) between our specimens and specimens of Equus caballus and Tapirus indicus, for the muscles of the forelimb.

Data for horses were all collected on adult specimens, and come from Payne, Veenman \& Wilson (2005) for the extrinsic muscles ( $n=7$ ), from Watson \& Wilson (2007) for the triceps, biceps and supraspinatus ( $n=2)$ and from Brown et al. (2003) for the muscles of the forearm $(n=7)$. Tapir data are from MacLaren \& McHorse (2020), and were gathered on one juvenile individual. CS: Ceratotherium simum, RU: Rhinoceros unicornis, AV.: average, EXT.: extrinsic muscles, SH.: muscles of the shoulder, ARM.: Muscles of the arm, FA.: muscles of the forearm, ND.: no data. Data were normalized ("\%" column) by dividing the PCSA by the average of the muscle group and multiplying by 100 . 
1 Table 4. Comparison of the PCSA (in $\mathrm{cm}^{2}$ ) between our specimens and specimens of Equus caballus and

2 Tapirus indicus for the muscles of the forelimb. Data for horses were all collected on adult specimens, 3 and come from Payne, Veenman \& Wilson (2005) for the extrinsic muscles $(n=7)$, from Watson \& 4 Wilson (2007) for the triceps, biceps and supraspinatus $(\mathrm{n}=2)$ and from Brown et al. (2003) for the 5 muscles of the forearm ( $\mathrm{n}=7)$. Tapir data are from MacLaren \& McHorse (2020), and were gathered on 6 one juvenile individual. CS: Ceratotherium simum, RU: Rhinoceros unicornis, AV.: average, EXT.: 7 extrinsic muscles, SH.: muscles of the shoulder, ARM.: Muscles of the arm, FA.: muscles of the forearm, 8 ND.: no data. Data were normalized ("\%" column) by dividing the PCSA by the average of the muscle 9 group and multiplying by 100 .

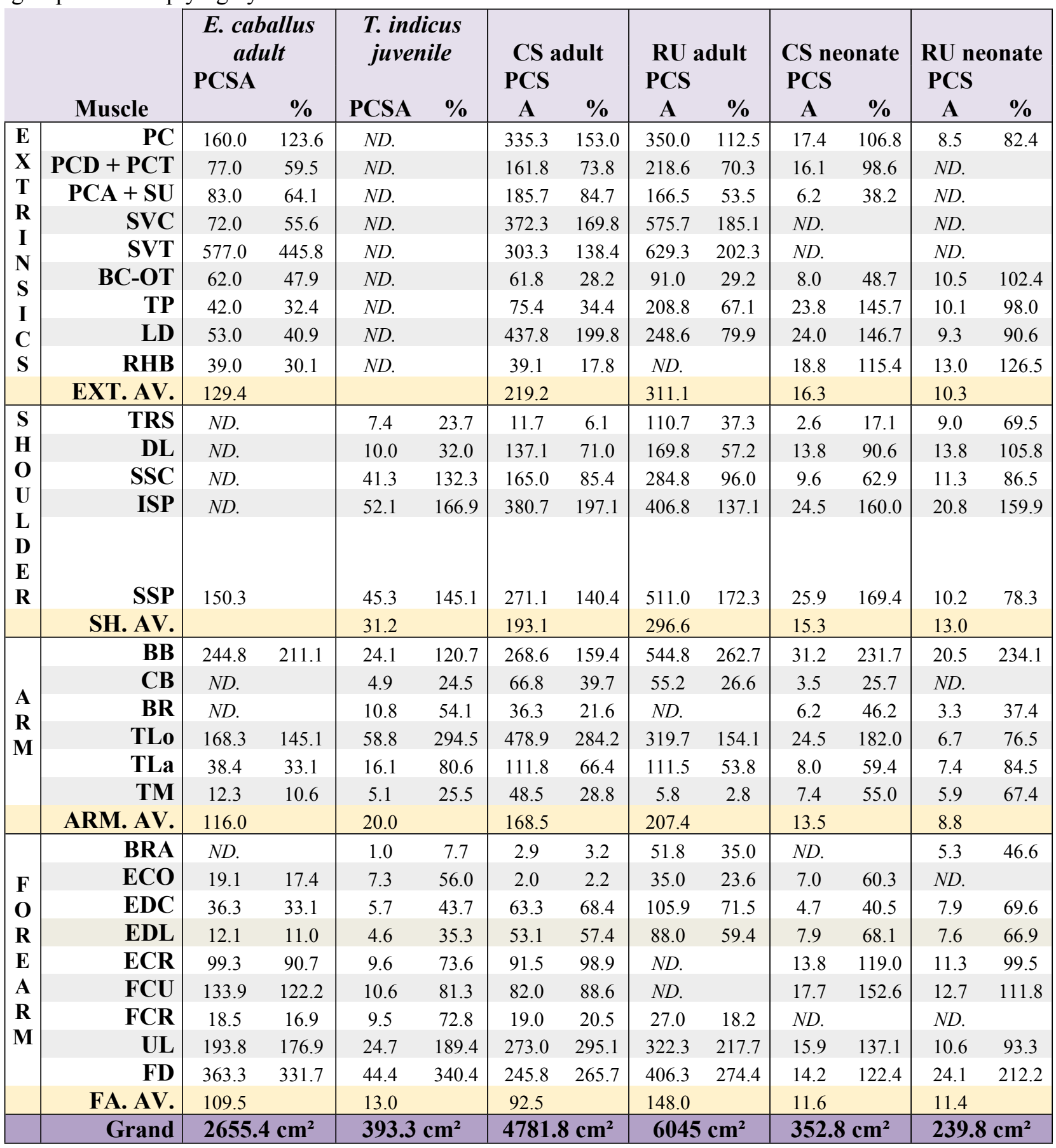




\begin{tabular}{|l|r|c|c|l|l|l|l|}
\hline Total & $\begin{array}{c}\text { Without } \\
\text { shoulder }\end{array}$ & $\begin{array}{l}\text { Without } \\
\text { extrinsic }\end{array}$ & & & & \\
\hline
\end{tabular}




\section{Table 5 (on next page)}

Comparison of the PCSA values (in $\mathrm{cm}^{2}$ ) between our specimens and specimens of Equus caballus, for the muscles of the hindlimb.

Data for horses were all collected on adult specimens, and come from Payne et al. (2005) (n = 7). CS: Ceratotherium simum, RU: Rhinoceros unicornis, AV.: average, PLV.: Muscles of the pelvis, TH.: muscles of the thigh, ND.: no data. Data were normalized ("\%" column) by dividing the PCSA by the average of the muscle group and multiplying by 100 . 
1 Table 5. Comparison of the PCSA values (in $\mathrm{cm}^{2}$ ) between our specimens and specimens of Equus 2 caballus for the muscles of the hindlimb. Data for horses were all collected on adult specimens, and come 3 from Payne et al. (2005) $(\mathrm{n}=7)$. CS: Ceratotherium simum, RU: Rhinoceros unicornis, AV.: average, 4 PLV.: Muscles of the pelvis, TH.: muscles of the thigh, ND.: no data. Data were normalized ("\%" 5 column) by dividing the PCSA by the average of the muscle group and multiplying by 100 .

\begin{tabular}{|c|c|c|c|c|c|c|c|c|c|c|c|}
\hline \multirow{2}{*}{\multicolumn{2}{|c|}{ Muscle }} & \multicolumn{2}{|c|}{ Equus adult } & \multicolumn{2}{|c|}{ CS adult } & \multicolumn{2}{|c|}{ RU adult } & \multicolumn{2}{|c|}{ CS neonate } & \multicolumn{2}{|c|}{ RU neonate } \\
\hline & & PCSA & $(\%)$ & PCSA & o) & PCSA & $\%)$ & PCSA & & PCSA & $(\%)$ \\
\hline \multirow{8}{*}{$\begin{array}{l}\mathbf{P} \\
\mathbf{E} \\
\mathbf{L} \\
\mathbf{V} \\
\mathbf{I} \\
\mathbf{S}\end{array}$} & GSP & 60.0 & 48.8 & 100.0 & 88.0 & 441.3 & 223.4 & 5.7 & 87.5 & 16.3 & 117.7 \\
\hline & GMD & 398.0 & 324.0 & 216.2 & 190.2 & 346.9 & 175.6 & 18.0 & 274.7 & 6.9 & 49.8 \\
\hline & GPF & 108.0 & 87.9 & 107.6 & 94.6 & 147.7 & 74.8 & 3.6 & 54.8 & $N D$. & \\
\hline & PMJ & 56.0 & 45.6 & 115.1 & 101.3 & 19.9 & 10.1 & 9.2 & 140.5 & $N D$. & \\
\hline & PMN & 61.0 & 49.7 & 65.5 & 57.6 & $N D$. & & 5.3 & 80.5 & 11.0 & 80.0 \\
\hline & IL & 54.0 & 44.0 & 73.4 & 64.6 & 63.0 & 31.9 & 2.9 & 44.1 & 21.1 & 152.6 \\
\hline & OG & $N D$ & & 117.9 & 103.7 & 166.2 & 84.1 & 1.2 & 17.8 & $N D$. & \\
\hline & PLV. AV. & 122.8 & & 113.7 & & 197.5 & & 6.5 & & 13.8 & \\
\hline \multirow{13}{*}{$\begin{array}{l}\mathbf{T} \\
\mathbf{H} \\
\mathbf{I} \\
\mathbf{G} \\
\mathbf{H}\end{array}$} & TFL & 140.0 & 85.3 & 213.8 & 198.5 & 455.4 & 201.5 & 12.6 & 112.6 & 15.2 & 132.7 \\
\hline & GB & 294.0 & 179.1 & 283.0 & 262.8 & 232.5 & 102.9 & 23.1 & 206.4 & 18.3 & 160.6 \\
\hline & ST & 144.0 & 87.7 & 101.2 & 93.9 & 166.8 & 73.8 & 10.3 & 92.0 & 7.2 & 63.1 \\
\hline & SM & 106.0 & 64.6 & 101.0 & 93.8 & 378.0 & 167.3 & 4.6 & 41.3 & 6.2 & 54.1 \\
\hline & VL & 105.0 & 64.0 & 117.3 & 109.0 & 179.5 & 79.4 & 10.4 & 93.1 & 11.8 & 103.5 \\
\hline & VI & 45.0 & 27.4 & ND. & & ND. & & $N D$. & & $N D$. & \\
\hline & VM & 148.0 & 90.2 & 95.3 & 88.5 & 105.0 & 46.5 & 10.6 & 94.9 & 8.2 & 71.8 \\
\hline & RF & 552.0 & 336.2 & 104.9 & 97.4 & 396.0 & 175.2 & 13.8 & 123.6 & 12.5 & 109.6 \\
\hline & PTN & 78.0 & 47.5 & 11.2 & 10.4 & 211.0 & 93.4 & 8.2 & 73.6 & 8.8 & 77.2 \\
\hline & SRT & 12.0 & 7.3 & 15.0 & 13.9 & 33.4 & 14.8 & 2.5 & 22.2 & 1.9 & 16.6 \\
\hline & GRC & 135.0 & 82.2 & 93.7 & 87.1 & 206.4 & 91.3 & 15.8 & 141.2 & 11.0 & 96.2 \\
\hline & ADD & 211.0 & 128.5 & 48.0 & 44.5 & 121.7 & 53.9 & 11.1 & 99.0 & 24.5 & 214.6 \\
\hline & TH. AV. & 164.2 & & 107.7 & & 226.0 & & 11.2 & & 11.4 & \\
\hline \multirow{7}{*}{$\begin{array}{l}\mathbf{L} \\
\mathbf{E} \\
\mathbf{G}\end{array}$} & GC & 298.0 & 109.0 & 200.6 & 165.1 & 222.2 & 162.6 & 12.5 & 135.6 & 13.4 & 110.0 \\
\hline & PP & 70.0 & 25.6 & ND. & & 26.9 & 19.7 & 2.9 & 31.4 & $N D$. & \\
\hline & TCR & 73.0 & 26.7 & 24.2 & 19.9 & 58.4 & 42.7 & 2.9 & 31.7 & 2.6 & 21.1 \\
\hline & EDLo & 54.0 & 19.7 & 56.6 & 46.6 & 117.1 & 85.7 & 10.4 & 112.9 & 7.1 & 57.8 \\
\hline & EDLaH & 26.0 & 9.5 & 8.3 & 6.8 & 31.3 & 22.9 & 1.8 & 19.4 & $N D$. & \\
\hline & FD & 1120.0 & 409.5 & 317.8 & 261.6 & 364.1 & 266.4 & 24.8 & 269.0 & 25.8 & 211.0 \\
\hline & LEG AV. & 273.5 & & 121.5 & & 136.7 & & 9.2 & & 12.2 & \\
\hline & $\begin{array}{l}\text { GRAND } \\
\text { TOTAL }\end{array}$ & 4348.0 & $\mathrm{~cm}^{2}$ & 2587. & $\mathrm{~cm}^{2}$ & 4490. & $\mathrm{~cm}^{2}$ & 224. & $\mathrm{~cm}^{2}$ & 229. & $\mathrm{~cm}^{2}$ \\
\hline
\end{tabular}

